\title{
Topological Insulator Film Growth by Molecular Beam Epitaxy: A Review
}

\author{
Theresa P. Ginley, Yong Wang and Stephanie Law * \\ Department of Materials Science and Engineering, University of Delaware, 127 The Green Room 201, \\ Newark, DE 19716, USA; ginley@udel.edu (T.P.G.); yongw@udel.edu (Y.W.) \\ * Correspondence: slaw@udel.edu; Tel.: +1-302-831-4816; Fax: +1-302-831-4545 \\ Academic Editor: Paul J. Simmonds
}

Received: 4 October 2016; Accepted: 18 November 2016; Published: 23 November 2016

\begin{abstract}
In this article, we will review recent progress in the growth of topological insulator (TI) thin films by molecular beam epitaxy (MBE). The materials we focus on are the $\mathrm{V}_{2}-\mathrm{VI}_{3}$ family of TIs. These materials are ideally bulk insulating with surface states housing Dirac excitations which are spin-momentum locked. These surface states are interesting for fundamental physics studies (such as the search for Majorana fermions) as well as applications in spintronics and other fields. However, the majority of TI films and bulk crystals exhibit significant bulk conductivity, which obscures these states. In addition, many TI films have a high defect density. This review will discuss progress in reducing the bulk conductivity while increasing the crystal quality. We will describe in detail how growth parameters, substrate choice, and growth technique influence the resulting TI film properties for binary and ternary TIs. We then give an overview of progress in the growth of TI heterostructures. We close by discussing the bright future for TI film growth by MBE.
\end{abstract}

Keywords: molecular beam epitaxy; topological insulator; superlattices

\section{Introduction}

Topological insulators (TIs) are materials with a band structure comprising a bulk bandgap crossed by surface states with linear dispersion [1-4]. These surface states exhibit spin-momentum locking, implying that the spin of a particle in these surface states is determined by its momentum [5]. This leads to a prohibition on backscattering and a reduction in scattering at other angles from nonmagnetic impurities, vacancies, and other defects, since a change in momentum requires a change in spin. However, surface electrons may still exhibit phonon scattering (though the strength of this interaction is not well-known) as well as interactions with bulk states, if available [6,7]. The linear dispersion of these states leads to essentially massless particles with a large Fermi velocity. If the Fermi energy of the TI can be placed within the bulk bandgap, all conduction will ideally take place on the surfaces, enabling the creation of devices which exploit the unusual properties of these surfaces. Applications of TIs include a platform for housing Majorana fermions, the creation of a large variety of spin devices, topological quantum computation, and others [8-12].

TIs were first predicted theoretically in two-dimensional $\mathrm{HgTe} / \mathrm{CdTe}$ quantum wells $[13,14]$. The realization that three-dimensional TIs could exist followed soon after [15-17]. Three-dimensional TIs were first experimentally demonstrated by imaging the band structure of the alloy $\mathrm{Bi}_{\mathrm{x}} \mathrm{Sb}_{1-\mathrm{x}}$ using angle resolved photoemission spectroscopy (ARPES) [18,19], closely followed by measurements of bulk crystals of $\mathrm{Bi}_{2} \mathrm{Se}_{3}, \mathrm{Bi}_{2} \mathrm{Te}_{3}$, and $\mathrm{Sb}_{2} \mathrm{Te}_{3}$ [1-4]. This confirmation of the existence of TIs led to an explosion of research in this field, both theoretically and experimentally. For a review of the history of the field, the reader is referred to [20]. As mentioned above, TI materials can be grown in bulk crystal form, from which thin films can be exfoliated. Additionally, thin films can be grown directly on a variety of substrates using chemical vapor deposition (CVD) techniques as well as molecular beam epitaxy 
(MBE), which will be the focus of this review [21]. MBE-grown films have a number of advantages over exfoliated films, including large area growth and the ability to controllably dope the materials, resulting in recent observations of the quantum anomalous Hall effect [22-27]. Unfortunately, both bulk crystals and thin films tend to exhibit significant conductivity from non-topological electrons, either from bulk states and/or from surface accumulation layers [28,29]. This is a particular problem for electrical measurements and applications, as the electrical signal from the non-topological electrons can overwhelm the signal from the surface states even in very thin films. Additionally, TIs frequently exhibit aging effects in which the film properties change over time, even in vacuum. In this review, we will discuss recent progress in the growth of TIs by MBE. First we will show the crystal structure of the $\mathrm{V}_{2} \mathrm{VI}_{3}$ compounds of interest, followed by a discussion of van der Waals epitaxy and substrate choice. We will then discuss each family of compounds in order, including binary and ternary films. We will end with a discussion of heterostructures, including TI structures and combined TI/band insulator (BI) materials.

\subsection{Crystal Structure}

Topological insulators are comprised of heavy elements with strong spin-orbit coupling. The strong spin-orbit coupling causes the valence band states to be pushed higher in energy than the conduction band states, leading to a band renormalization. As a first approximation, one can now imagine that the bottom of the conduction band near the $\Gamma$ point is comprised of states with the symmetry of the valence band, and the top of the valence band is comprised of states with the symmetry of the conduction band. This is an inverted band structure. At the surfaces of the TI, this inverted band structure interfaces with a normal band structure. Boundary conditions require that the valence band states in the TI which have conduction band character connect with the conduction band in the normal material, and vice versa. This leads to the surface states which are of interest in TI materials. These surface states are depicted in the calculated $\mathrm{Bi}_{2} \mathrm{Se}_{3}$ band structure shown in Figure 1. To first order, the spin-momentum locking of the surface electrons comes from the strong spin-orbit coupling of the heavy elements that comprise the material. This explanation of TI behavior is quite basic and ignores many complications, but it is sufficient to see that strong spin-orbit coupling is required for the formation of a strong TI. For a more thorough treatment of the theory behind the TI band structure, the reader is referred to [12]. The prototypical TI materials are $\mathrm{Bi}_{2} \mathrm{Se}_{3}, \mathrm{Bi}_{2} \mathrm{Te}_{3}, \mathrm{Sb}_{2} \mathrm{Te}_{3}$, and their alloys. These materials have been known for many years as good thermoelectrics and were grown by MBE for that purpose long before they were investigated for their topological properties.

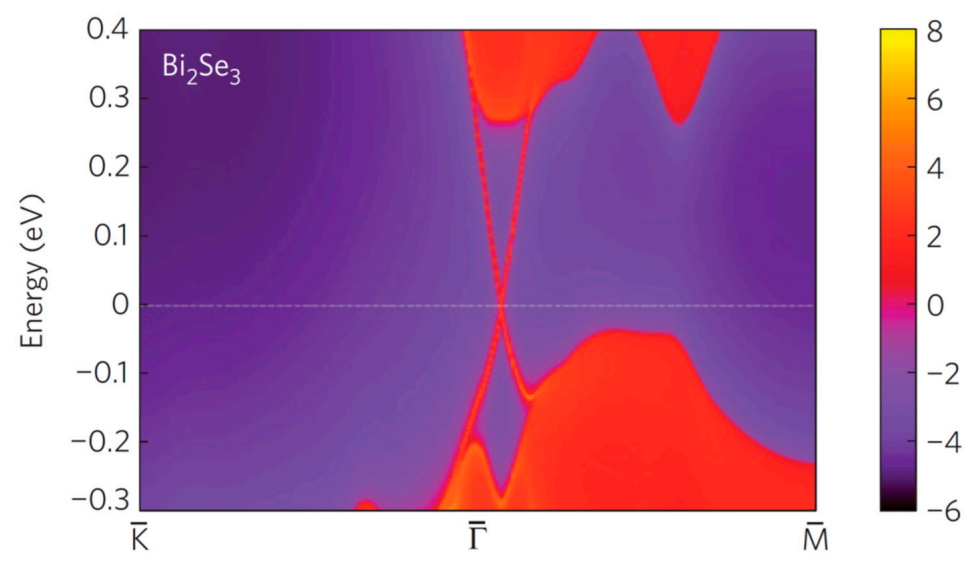

Figure 1. Calculated band structure of $\mathrm{Bi}_{2} \mathrm{Se}_{3}$ showing the linear dispersion of the surface states. Reproduced with permission from Zhang et al., Nature Physics; published by Nature Publishing Group, 2009 [5]. 
The crystal structure of $\mathrm{Bi}_{2} \mathrm{Se}_{3}$ is shown in Figure 2. It is a tetradymite structure with space group $D_{3 d}^{5}(R \overline{3} m)$. The other TI materials discussed in this review have the same structure. The basic building block of the chalcogenide TIs is the quintuple layer (QL); two QLs are shown in Figure 2(a). Each QL is $\sim 1 \mathrm{~nm}$, though precise values vary from compound to compound. The stacking structure within a QL is Se1-Bi-Se2-Bi-Se1. Each QL is chemically stable, leading to a van der Waals gap between QLs. This weak interlayer bonding allows TI layers to easily be exfoliated from bulk crystals. It also allows MBE growth to take place on a wide variety of substrates, since the film is only weakly bound to the substrate. This type of growth is traditionally called van der Waals epitaxy [30,31]. However, there is evidence that choosing lattice-matched substrates can significantly improve the film growth, as will be discussed in detail in this article.
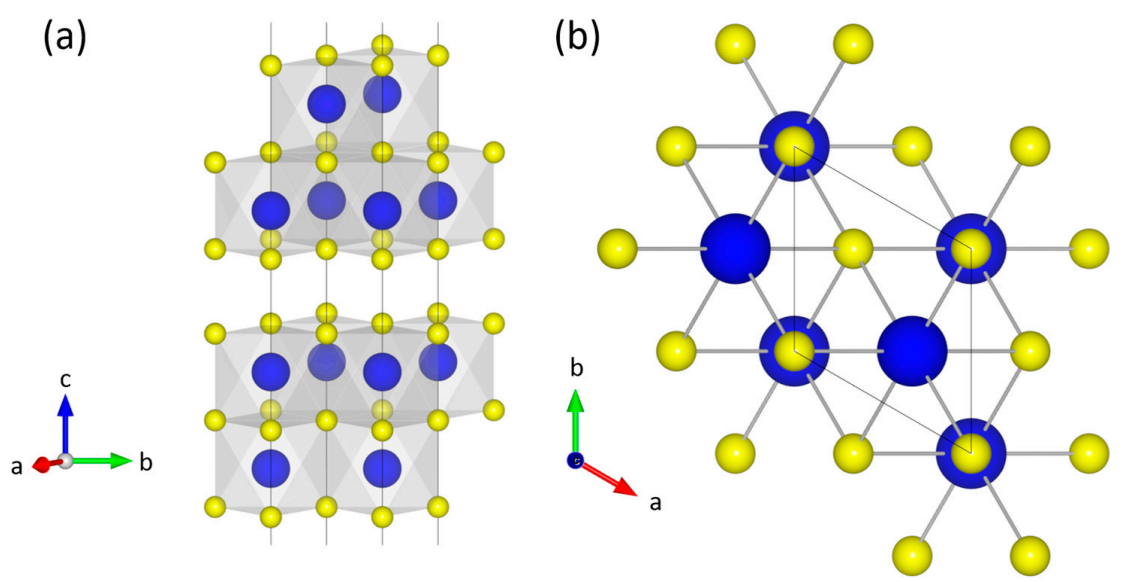

Figure 2. Crystal structure of tetradymite $\mathrm{Bi}_{2} \mathrm{Se}_{3}$ (other TI materials are similar). Bi atoms are large and shown in blue while Se atoms are smaller and shown in yellow. (a) Crystal structure along the a-b plane showing two quintuple layers with the van der Waals gap between them. (b) Crystal structure along the c-axis. Structure created with VESTA [32].

\subsection{Substrate Choice}

The most common substrate used for MBE growth of TIs is c-plane sapphire $\left(\mathrm{Al}_{2} \mathrm{O}_{3}\right)$ which has the same in-plane structure as the TIs. Almost all $\mathrm{Bi}_{2} \mathrm{Se}_{3}$ growth takes places on sapphire [33], though other materials are frequently grown on other substrates, as described in detail in Section 2. Sapphire has a variety of advantages, including its low cost, easy availability, high surface quality, and general chemically inert behavior. However, there is some evidence that the large lattice mismatch between sapphire and TIs (almost $15 \%$ for $\mathrm{Bi}_{2} \mathrm{Se}_{3}$ ) can lead to a variety of structural defects, including mosaicity-tilt, mosaicity-twist, antiphase domain boundaries (APBs), and twin defects [34-37]. In Figure 3, we present a plot of lattice constant for some of the common TIs and the available substrates.

The difficulty in using many of the more closely lattice-matched substrates is the presence of dangling bonds and surface oxide layers. InP (111), for example, is closely lattice-matched to $\mathrm{Bi}_{2} \mathrm{Se}_{3}$. However, InP has a surface oxide that is normally thermally desorbed at a relatively high temperature. This high temperature leads to phosphorous outgassing from the sample, which must be compensated. In a traditional III/V chamber, a phosphorous flux is easy to supply, but this becomes much more difficult in a chalcogenide-only chamber. Some success has been obtained by supplying the chalcogenide atom in excess when desorbing surface oxides from III/V and other substrates [38]. In addition to surface oxides, a large fraction of the available substrates have surface dangling bonds which must be satisfied. Again, there has been some success in passivating these surfaces by supplying a chalcogenide overpressure [39-41] or by depositing a monolayer of bismuth [42]. These growth challenges as well as the relatively high cost of many lattice-matched substrates is why most growth continues on sapphire. 


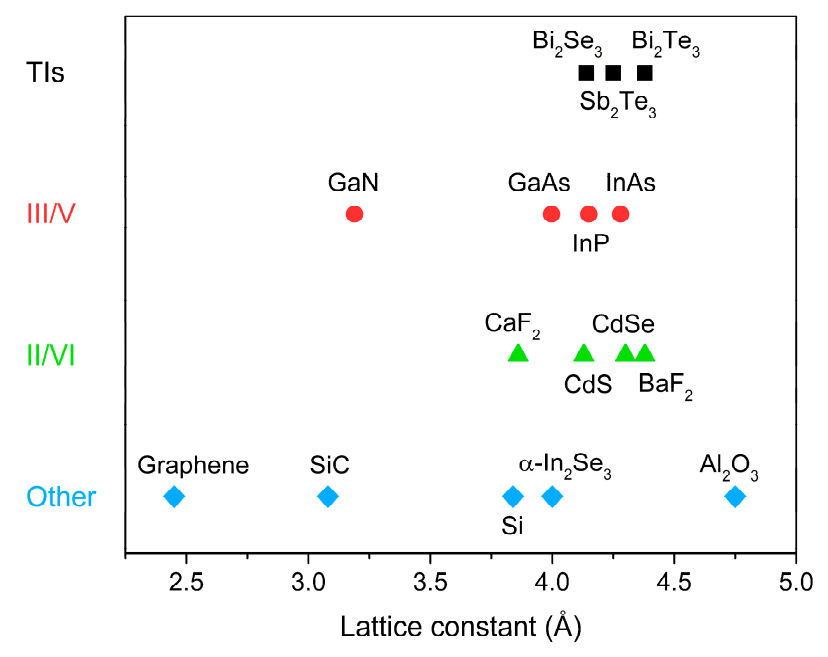

Figure 3. Lattice constants of various substrates compared to lattice constants of binary TIs. For zincblende and cubic structures, the lattice constant of the (111) face is given. For wurtzite structures, graphene, $\mathrm{In}_{2} \mathrm{Se}_{3}$ and $\mathrm{Al}_{2} \mathrm{O}_{3}$, the lattice constant of the hexagonal (001) face is given.

There have been recent promising reports of $\mathrm{Bi}_{2} \mathrm{Se}_{3}$ grown using buffer layers or virtual substrates. $\mathrm{In}_{2} \mathrm{Se}_{3}$ is a trivial band insulator with the same layered crystal structure and similar lattice constant to the TIs discussed in this article. Thus, theoretically, using $\mathrm{In}_{2} \mathrm{Se}_{3}$ as a buffer layer could enhance the crystal quality of $\mathrm{Bi}_{2} \mathrm{Se}_{3}$ films. Systematic optimization of MBE growth parameters of $\mathrm{In}_{2} \mathrm{Se}_{3}$ on $\mathrm{Si}(111)$ substrate was reported by Rathi et al. [43]. The authors concluded that the $\operatorname{In}_{2} \mathrm{Se}_{3}$ layers that are most suitable for $\mathrm{Bi}_{2} \mathrm{Se}_{3}$ growth resulted from a three-step growth sequence: Se passivation of the Si substrate at $100{ }^{\circ} \mathrm{C}, \mathrm{In}_{2} \mathrm{Se}_{3}$ codeposition with a temperature ramp from $100{ }^{\circ} \mathrm{C}$ to $400{ }^{\circ} \mathrm{C}$, followed by Se anneal at $400{ }^{\circ} \mathrm{C}$. They also successfully grew $\mathrm{Bi}_{2} \mathrm{Se}_{3}$ on top of $\mathrm{In}_{2} \mathrm{Se}_{3}$ with a sharp interface. Koirala et al. [44] reported that using $\left(\mathrm{In}_{\mathrm{x}} \mathrm{Bi}_{1-\mathrm{x}}\right)_{2} \mathrm{Se}_{3}$ as a buffer layer between $\mathrm{Bi}_{2} \mathrm{Se}_{3}$ and sapphire substrate reduced defects in the $\mathrm{Bi}_{2} \mathrm{Se}_{3}$ crystal and caused an order of magnitude enhancement in the mobility over films grown without the buffer layer. Further discussion of substrate choice for different material systems will be described within each topic below, but these results indicate that substrate choice and preparation is crucial for high-quality growth of TIs.

\subsection{Aging Effects}

One of the other challenges when working with TIs is the effect of aging. ARPES measurements performed on newly grown thin films and freshly cleaved bulk crystals for $\mathrm{Bi}_{2} \mathrm{Se}_{3}$ and $\mathrm{Bi}_{2} \mathrm{Te}_{3}$ frequently show a surface Fermi level within the bulk bandgap, above the Dirac point. Over the course of a few days in vacuum or a few hours in air, the Fermi level rises into the conduction band [45-51]. The case of $\mathrm{Sb}_{2} \mathrm{Te}_{3}$ is somewhat different, with the Fermi level of new films and freshly cleaved crystals residing below the Dirac point, frequently in the valence band. There are few reports of how the band structure of these material changes over time, but the existing data indicate a relatively stable Fermi energy despite the large background doping, in contrast to the bismuth-based materials [4,52-54]. The exact mechanism behind the change in Fermi level in $\mathrm{Bi}_{2} \mathrm{Se}_{3}$ and $\mathrm{Bi}_{2} \mathrm{Te}_{3}$ is not well known, but it is thought to be due to a combination of selenium/tellurium outgassing from the film, oxygen diffusing into vacancies, and adsorption of other gasses on the film surface. This results in bands which normally bend downward at the surface, leading to a surface accumulation layer with the Fermi level in the conduction band and a trivial two-dimensional electron gas (2DEG) at the surface, as shown in Figure 4 . Although this aging effect makes it more difficult to observe the effects of the surface states due to the increase in the trivial carrier density, the surface states still exist within the film. 

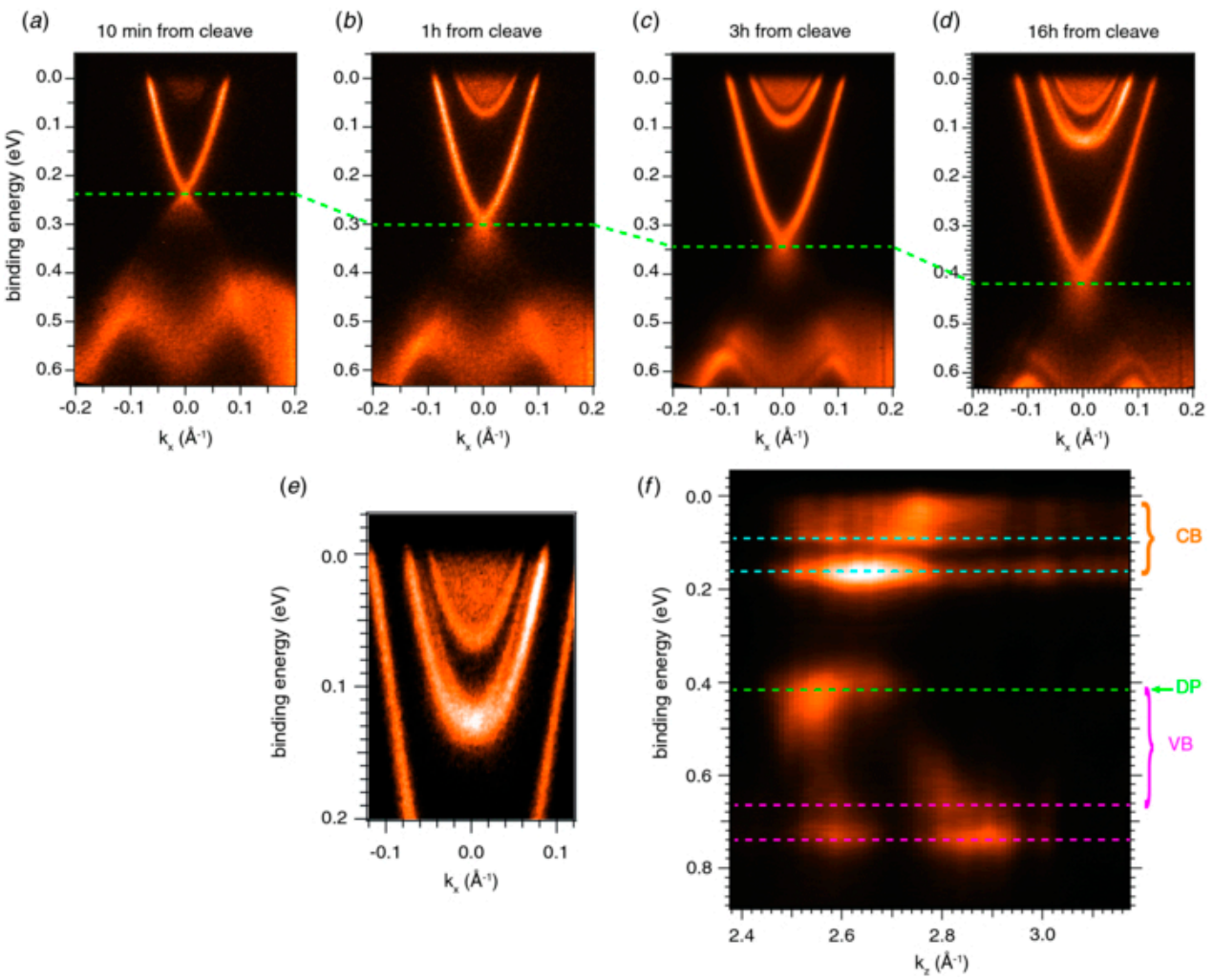

Figure 4. ARPES scans of bulk $\mathrm{Bi}_{2} \mathrm{Se}_{3}$ crystals taken at (a) $10 \mathrm{~min},(\boldsymbol{b}) 1 \mathrm{~h},(\boldsymbol{c}) 3 \mathrm{~h}$ and (d) $16 \mathrm{~h}$ after cleaving. As time passes, the Dirac point shifts lower and additional conduction band states from band bending become visible. (e) Magnification of the conduction band from $(d)$ showing the Rashba split quantum well states. $(f)$ Photoemission intensity at normal emission as a function of binding energy and $k_{z}$ acquired with a photon energy scan. Reproduced with permission from Bianchi et al., Semiconductor Science and Technology; published by IOP Science, 2012 [50].

\subsection{TI Film Structural Quality}

As mentioned previously, TI films can suffer from a variety of structural defects, including mosaicity-tilt, mosaicity-twist, antiphase domain boundaries (APBs), stacking faults, and twin defects [34-37]. Details about these defects and strategies to reduce them will be discussed for each material class separately in Section 2, but we will give an overview of the subject here. It should be emphasized that the topological surface state is robust and exists even in defective films. For electrical devices, the most important metrics of film quality are carrier density and mobility—high quality TI films should have a low trivial carrier density and a high mobility for the electrons in the surface states. Trivial carrier density tends to be determined by point defects, including vacancies and antisite defects, as well as surface band bending, as discussed in detail in Section 2. Mobility is determined both by point defects as well as by the line and planar defects as listed above.

Due to the in-plane three-fold symmetry of the crystal (shown in Figure 2b), TI materials are highly susceptible to structural defects. There are three possible orientations for a TI domain, $A, B$, and $C$. A perfect stacking sequence in the growth direction would be $A B C A B C A B C$, with each QL rotated $120^{\circ}$ from the previous QL. A stacking fault occurs when a single $\mathrm{QL}$ is removed, leading to a sequence of e.g., $A B A B C A B C$, or when a single $\mathrm{QL}$ is added, leading to a sequence of e.g., $A B B C A B C A B C$, as shown schematically in Figure 5. Stacking faults may have profound effects on the electrical properties of the film, including forming topologically protected states along the fault or shifting the Dirac point with respect to the pristine band structure [55]. These types of defects are generally difficult to prevent. 

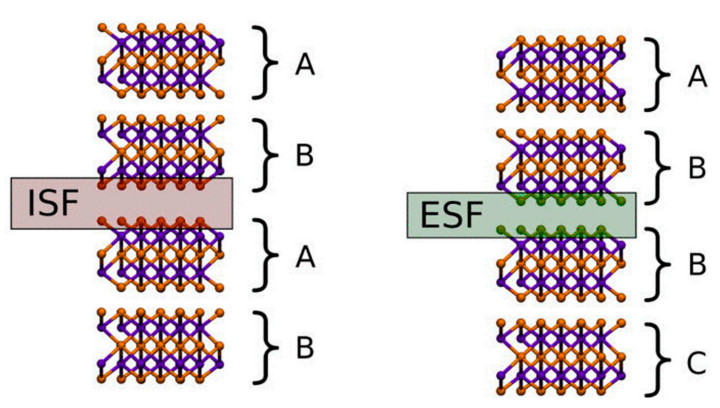

Figure 5. The two types of stacking faults (ISF, or intrinsic stacking fault, and ESF, or extrinsic stacking fault) possible in a TI film. Reproduced with permission from Seixas et al., Journal of Applied Physics; published by the American Institute of Physics, 2013 [55].

Twin defects occur when two domains with different stacking sequences meet. Twin defects occur over a much larger area than stacking faults. A change in stacking in the vertical direction leads to a lamellar twin, while a change in stacking in the plane leads to a rotational twin. Rotational twin defects appear as oppositely-oriented triangular domains in atomic force microscopy (AFM) scans (see Section 2.1.3; both types of twin defects can be viewed using transmission electron microscopy (TEM) $[34,42,56]$. In general, a higher structural quality film will show fewer, larger triangular domains, which correlates with a higher mobility (see Table 1). The domain size generally becomes larger when the film is grown on a lattice-matched substrate or through optimizing the substrate temperature, growth rate, and flux ratios [34,37,42,57,58]. Details regarding growth techniques to reduce twinning are given in Section 2.

Antiphase domains occur due the difference in unit cell height between the substrate and the TI film. The substrate is comprised of large, flat terraces with step heights equal to the substrate unit cell size. One TI film domain may nucleate on a terrace that is higher than the terrace on which the next TI film domain nucleates. When these two domains meet, an antiphase domain will form in which the unit cell of the TI is shifted vertically by the height of one atomic step in the underlying substrate. This type of defect has a negative influence on the electrical properties of the film [34,41] and is difficult to remove without growing on isostructural substrates, though ideas for reducing antiphase domains are discussed below.

Finally, mosaicity-twist and mosaicity-tilt both occur when the film nucleates in many small domains. If these domains are slightly rotated with respect to one another in the plane of the film, that is mosaicity-twist. If the domains are slightly misaligned out-of-plane, that is mosaicity-tilt. The degree of mosaicity can be measured by x-ray diffraction studies. For $\mathrm{Bi}_{2} \mathrm{Se}_{3}$ films, mosaicity is generally low and does not have a strong effect on the film transport properties, though the roughness of the substrate can increase this effect $[34,37]$.

In general, structural defects in TI films can have large, negative effects on the transport properties of the film. Although the topological surface states will still exist even in a defective film, the mobility of those states may be lower than in a perfect film and the topologically protected states may be more difficult to distinguish from trivial states. In the next Section, techniques for reducing structural defects are discussed for a variety of TI materials on a variety of substrates.

\section{Binary Materials (E.G. $\mathrm{Bi}_{2} \mathrm{Se}_{3}, \mathrm{Bi}_{2} \mathrm{Te}_{3}, \mathrm{Sb}_{2} \mathrm{Te}_{3}$ )}

We will begin our discussion of specific TI material growth with the common binary compounds: $\mathrm{Bi}_{2} \mathrm{Se}_{3}, \mathrm{Bi}_{2} \mathrm{Te}_{3}$, and $\mathrm{Sb}_{2} \mathrm{Te}_{3}$. A great deal of promising work has been done on binary compounds since the growth parameters for these materials are relatively easy to determine. Many groups have been able to achieve high quality binary topological insulators, however each of these compounds have drawbacks that limit their individual quality. $\mathrm{Bi}_{2} \mathrm{Se}_{3}$ has a tendency to form selenium vacancies. $\mathrm{Bi}_{2} \mathrm{Te}_{3}$ forms antisite defects and has a Dirac point buried in the valence band, making it difficult 
to access. These will be discussed in further detail in later sections. Once the binary growths are optimized and the materials well-characterized, alloys can be formed to further tailor materials and highlight TI properties, as discussed in Section 3.

\section{1. $\mathrm{Bi}_{2} \mathrm{Se}_{3}$}

Bismuth selenide is perhaps the most widely studied of the binary topological insulators due to its relatively large bulk band gap of $\sim 0.3 \mathrm{eV}$ around the Dirac point [5]. This band structure can provide clear access to the topological surface states and the Dirac point if the Fermi level can be tailored to lie in the bandgap. Unfortunately, this has proven to be quite challenging, and $\mathrm{MBE}$ grown $\mathrm{Bi}_{2} \mathrm{Se}_{3}$ tends to remain bulk $n$-type. The most commonly accepted explanation for the bulk conductivity is that these films are prone to selenium vacancy defects, resulting in electron-type doping [59,60]. $\mathrm{Bi}_{2} \mathrm{Se}_{3}$ also tends to exhibit aging effects in which the film electrical properties change with time. Selenium vacancies may also be to blame in this case, as these missing atoms may make it easier for oxygen to diffuse into the films. In this section, we will review standard growth procedures for $\mathrm{Bi}_{2} \mathrm{Se}_{3}$ and the resulting material properties, followed by unconventional approaches and their results.

\subsubsection{Standard Growth Parameters}

As discussed in Section 1.2, most growth of $\mathrm{Bi}_{2} \mathrm{Se}_{3}$ take place on sapphire substrates, relying on van der Waals epitaxy to overcome the lattice mismatch of $~ 15 \%$. Standard Knudsen-type effusion cells (K-cells) are conventionally used to supply the selenium. K-cells evaporate large selenium molecules $\left(\mathrm{Se}_{6}, \mathrm{Se}_{7}, \mathrm{Se}_{8} \ldots\right)$ which must break apart at the growth surface to incorporate into the film [61]. Selenium also outgasses easily from the films during growth, despite the relatively low substrate temperatures (typically $250-350^{\circ} \mathrm{C}$ ). To overcome both the inefficient incorporation and the persistent outgassing, films are typically grown using a large selenium over pressure (15:1-20:1 Se:Bi) and the bismuth flux is used to control the growth rate, similar to standard III/V semiconductor growth protocols. The selenium flux is usually maintained after the growth to prevent outgassing while the substrate is cooling. As discussed in Section 2.1.5, a cracking source can be used to break apart the large selenium molecules to improve incorporation into the film, though cracked selenium is somewhat corrosive to the metallic MBE components. Growth rates for $\mathrm{Bi}_{2} \mathrm{Se}_{3}$ are usually around $1 \mathrm{QL} / \mathrm{min}$ $(\sim 0.8-0.9 \mathrm{~nm} / \mathrm{min})[42,62]$.

\subsubsection{Electrical Properties/ARPES}

The growth parameters discussed in Section 2.1.1 have yielded good-quality films and serve as a baseline for comparing different growth methods. For electrical device applications, the most important film characteristics are carrier mobility and concentration. An ideal topological insulator will have unimpeded electron flow through the surface states and no bulk carriers, so the MBE grown films should display high mobility and low carrier concentration. Using standard growth parameters, mobilities of 500-1000 $\mathrm{cm}^{2} / \mathrm{Vs}$ are usually reported with corresponding sheet densities in the mid $10^{13} \mathrm{~cm}^{-2}$. While these findings are promising, they all demonstrate the presence of non-topological carriers upon exposure to atmosphere and suggest a Fermi level residing in the bulk conduction band. This can be confirmed by angle resolved photoemission spectroscopy (ARPES) studies of the films. ARPES measures photoelectrons emitted after excitation via soft $x$-ray to map the electron distribution (and therefore the band structure) in a material relative to the Fermi level. It is an extremely surface sensitive measurement that is able to show the bulk bands, the topological surface states, and whether the Fermi level lies in the band gap. ARPES results confirm that even the best films grown via K-cell on sapphire substrates have their Fermi level pinned at best near the bottom of the conduction band. A typical ARPES scan of $\mathrm{Bi}_{2} \mathrm{Se}_{3}$ is shown in Figure 6. 


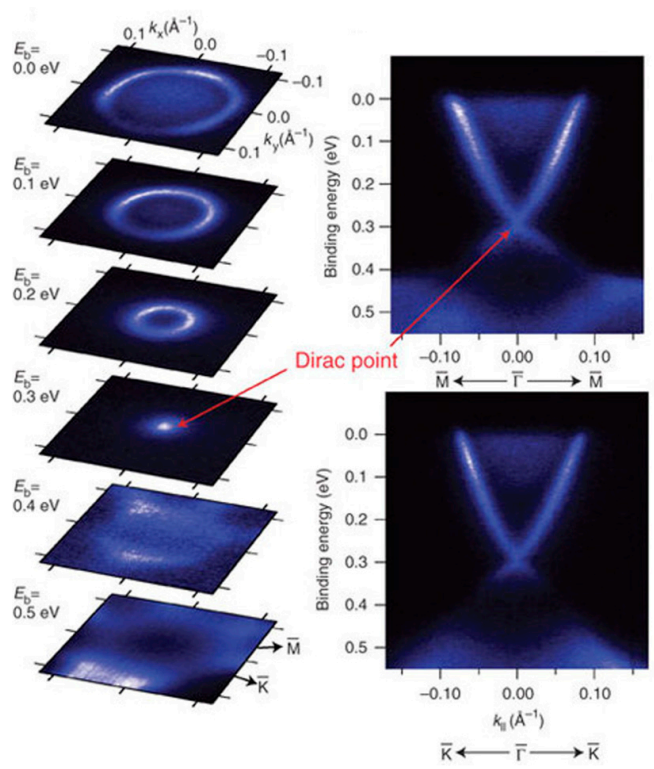

Figure 6. ARPES measurement of bulk $\mathrm{Bi}_{2} \mathrm{Se}_{3}(0001)$. The topological surface states can be seen as the bright lines crossing the bulk bandgap. Reproduced with permission from Bianchi et al., Nature Communications; published by Nature Publishing Group, 2010 [29].

\subsubsection{Atomic Force Microscopy}

AFM scans done on $\mathrm{Bi}_{2} \mathrm{Se}_{3}$ films typically exhibit pyramid structures, as shown in Figure 7. The pyramids are likely caused by the rotational symmetry of the triangular in-plane lattice of the $\mathrm{Bi}_{2} \mathrm{Se}_{3}$ film, allowing islands to nucleate in different orientations, creating twining and other structural defects. Growth on vicinal or rough surfaces forces the nucleated islands to align along step edges and reduces twin defects [57]. Films with the best electrical properties tend to have fewer yet larger pyramids. This can be attributed to different growth conditions. When the surface mobility during growth is high enough, the bismuth and selenium adatoms have time to diffuse to the most energetically favorable positions. This will reduce the number of vacancy defects (improving electrical properties) and allow individual domains to grow larger (resulting in fewer but lager pyramids). If surface mobility is low, due to a low substrate temperature or high growth rate, adatoms will have less time to find favorable positions and more vacancy defects and pyramids will form. In very thin films (6-20 nm), $\mathrm{Bi}_{2} \mathrm{Se}_{3}$ tends to form many small triangular terraces, which is indicative of island formation in the early stages of growth. Island formation, or Volmer-Weber growth, is due to the domination of adatom-adatom interactions over adatom-substrate interactions. As films become thicker, the islands grow and merge, leading to fewer but larger pyramids. This is indicative of a switch to step flow growth along the edges of the terraces. The changeover to step flow growth indicates that the adatoms have a higher mobility on a completed $\mathrm{Bi}_{2} \mathrm{Se}_{3}$ QL than on the substrate, most likely due to the van der Waals bonding between QLs.
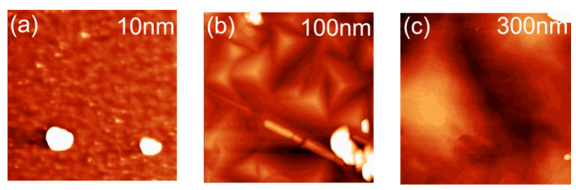

Figure 7. $2 \times 2 \mu \mathrm{m}$ atomic force microscopy images of $\mathrm{Bi}_{2} \mathrm{Se}_{3}$ films of thickness (a) $10 \mathrm{~nm}$, (b) $100 \mathrm{~nm}$, and (c) $300 \mathrm{~nm}$. Color scale for (a) is $0-8 \mathrm{~nm}$, for (b) is $0-10 \mathrm{~nm}$, and for (c) is $0-60 \mathrm{~nm}$. The triangular terraces grow larger and merge as the film becomes thicker. Reproduced with permission from Ginley et al., Journal of Vacuum Science and Technology B; published by the American Vacuum Society, 2016 [62]. 


\subsubsection{Substrate Choice}

As previously mentioned, the van der Waals bonding between QLs allows $\mathrm{Bi}_{2} \mathrm{Se}_{3}$ to be grown on a wide range of substrates regardless of lattice mismatch. This is an extremely useful property for incorporating TIs into devices or studying their optical or electrical properties. Substrate choice is extremely customizable for specific applications. Growth parameters on different substrates tend to be very similar, with the largest differences being substrate preparation and temperature during growth. For example, growth on GaAs (111)B [36] and GaAs (001) [63,64] is best when a slightly higher substrate temperature is used than for growth on sapphire. Using these substrates also requires more careful substrate preparation, including desorption of the surface oxide layer in an arsenic flux followed by growth of a GaAs a buffer layer to create an extremely flat surface. These growth parameters yielded films with carrier densities of $8.06 \times 10^{18} \mathrm{~cm}^{-3}$ to $4 \times 10^{19} \mathrm{~cm}^{-3}$ and mobilities in the range $\sim 100-\sim 1000 \mathrm{~cm}^{2} /(\mathrm{Vs})$. Similar results have been found for growths on $\mathrm{Si}(111), \mathrm{SiO}_{2} / \mathrm{Si}$, $\mathrm{GaN}$ [42], $\mathrm{BaF}_{2}, \mathrm{InP}, \mathrm{SrTiO}_{3}$, and graphene [65,66]. An overview of film properties as a function of substrate choice can been seen in Table 1 . Below, interesting findings and substrates for unique applications will be discussed in greater detail.

A study of TIs grown on InP with varying substrate surface roughness provided valuable insight into the effect of substrate roughness on TI film quality [34]. The study showed that substrates with rougher surfaces led to fewer twin boundaries and decreased surface roughness in the TI films. These results led to the conclusion that $\mathrm{Bi}_{2} \mathrm{Se}_{3}$ aligns itself to rough substrates by beginning growth in the hollows. While this does help to decrease twin defects, it also increases antiphase domain boundaries since not all of the hollows will be of equal depth. Xie et al. also did studies on $\operatorname{InP}(111)$ that support this finding [67]. When substrates were prepared to have large flat terraces, the $\mathrm{Bi}_{2} \mathrm{Se}_{3}$ film grew via island nucleation and twin domains were observed. However, on rougher substrates, $\mathrm{Bi}_{2} \mathrm{Se}_{3}$ films grew via a step flow growth method, and single-domain films were consistently observed. The strong interaction between InP substrates and $\mathrm{Bi}_{2} \mathrm{Se}_{3}$ films has led Guo et al. to suggest that these films are not grown by van der Waals epitaxy at all [38]. It may be that the low lattice mismatch between $\mathrm{Bi}_{2} \mathrm{Se}_{3}$ and $\mathrm{InP}(\sim 3 \%)$ allows the substrate to have a greater influence on the subsequent film growth. These findings suggest that a film patterned to have controlled roughness of equal depth across the substrate would result in a film with very few structural defects. Growing on vicinal substrates has yielded similar results, with the step edges serving as nucleation points and forcing an orientation in the initial $\mathrm{Bi}_{2} \mathrm{Se}_{3}$ layer. Growth on vicinal $\mathrm{Si}(111)$ resulted in a mobility of $\sim 1600 \mathrm{~cm}^{2} \cdot \mathrm{V}^{-1} \cdot \mathrm{s}^{-1}$ and a 3D carrier concertation of $\sim 5 \times 10^{18} \mathrm{~cm}^{-3}$, as compared to $\sim 1200 \mathrm{~cm}^{2} \cdot \mathrm{V}^{-1} \cdot \mathrm{s}^{-1}$ and $\sim 3 \times 10^{19} \mathrm{~cm}^{-3}$ on nonvicinal $\mathrm{Si}(111)$ by the same group [57].

Silicon is an attractive choice of substrate material for TI films due to its prevalence in electronic devices. One difficulty in using silicon is the presence of dangling bonds after the removal of the native oxide. If the dangling bonds are left unpassivated before TI growth begins, a layer of $\mathrm{SiSe}_{2}$ may form at the substrate interface [40] or a single crystal $\mathrm{Bi}_{2} \mathrm{Se}_{3}$ film may never be achieved [42]. One way to passivate the dangling bonds is to expose the film to a bismuth or selenium flux after the oxide is removed but before the TI growth begins. While bismuth exposure only provides a slight improvement over passivated Si films [42], selenium exposure has shown very promising results given the correct conditions. Bansal et al. found that a substrate temperature of approximately $100^{\circ} \mathrm{C}$ during selenium exposure produced a self-limiting selenium passivation layer leading to an atomically sharp interface with the substrate [40]. Selenium passivation has also been successfully demonstrated on GaAs [68] and $\mathrm{SiO}_{2} / \mathrm{Si}$ films. Another approach to surface passivation is the growth of a buffer layer with a layered structure, such as $\mathrm{GaSe}, \mathrm{ZnSe}$, or $\mathrm{In}_{2} \mathrm{Se}_{3}$. The latter in particular has shown very promising results due to its similar structure and small lattice misfit ( 3.4) to $\mathrm{Bi}_{2} \mathrm{Se}_{3}$ [69]. Even when substrate passivation is not needed, using an $\mathrm{In}_{2} \mathrm{Se}_{3} /\left(\mathrm{Bi}_{\mathrm{x}} \mathrm{In}_{1-\mathrm{x}}\right)_{2} \mathrm{Se}_{3}$ buffer layer has resulted in greatly improved electrical properties. The use of such a buffer between a sapphire substrate and a $\mathrm{Bi}_{2} \mathrm{Se}_{3}$ film resulted in 2D sheet densities as low as $1-3 \times 10^{12} \mathrm{~cm}^{-2}$, allowing for the first successful observation of the Quantum Hall Effect in $\mathrm{Bi}_{2} \mathrm{Se}_{3}$ films [44]. However, incorporating a buffer layer can prove challenging 
if growth temperatures for the buffer layer and the TI film differ greatly. This is especially important for growth on Si substrates, which require a substrate temperature as low as $150{ }^{\circ} \mathrm{C}$ for $\mathrm{Bi}_{2} \mathrm{Se}_{3}$ growth [39]. For an overview of silicon passivation and buffer layers for $\mathrm{Bi}_{2} \mathrm{Se}_{3}$, see Wang et al [42]. The methods used to prepare silicon substrates for good growths shed light on the importance of the substrate/film interface for the growth of good TI films, despite the use of van der Waals epitaxy. Applying similar techniques to other substrates may allow $\mathrm{Bi}_{2} \mathrm{Se}_{3}$ to be grown on an even wider variety of substrates.

Table 1. Electrical properties of binary TIs. Where data was available, columns give TI material, the substrate on which it was grown, mobility $(\mu)$, sheet density $\left(n_{2 D}\right)$, bulk density $\left(n_{3 D}\right)$, film thickness $(t)$, and temperature at which the electrical measurements were performed $(T)$.

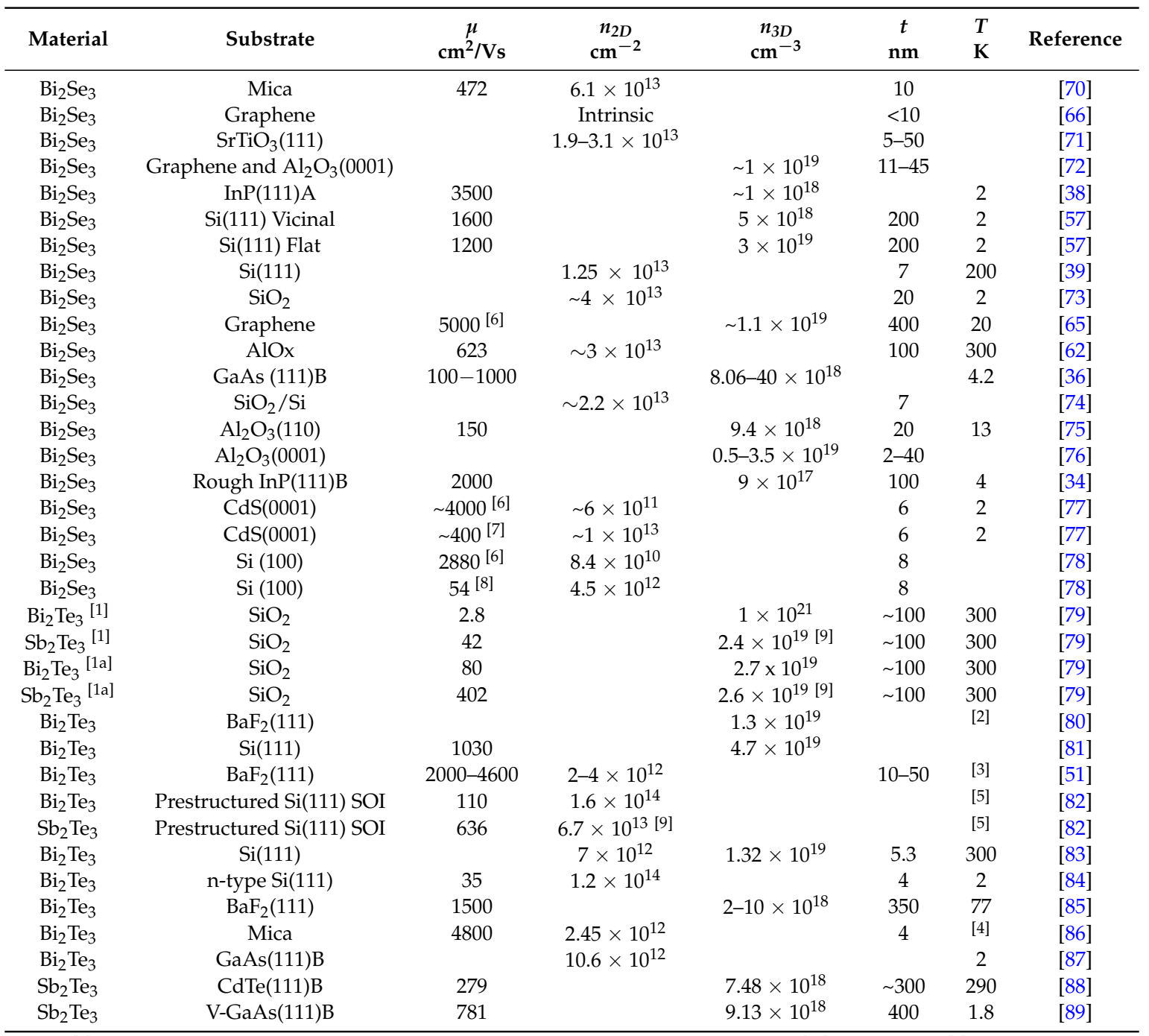

${ }^{[1]}$ Films were grown at room temperature, then annealed, as indicated with the ${ }^{[1 \mathrm{a}]}$ superscript; ${ }^{[2]}$ Calculated from Seebeck measurements; ${ }^{[3]}$ Calculated from ARPES measurements; ${ }^{[4]}$ Calculated from Schubnikov-de Haas measurements; ${ }^{\left[{ }^{[}\right]}$Data was taken at low temperature, no absolute value given; ${ }^{[6]}$ Calculated for TI surface; ${ }^{[7]}$ Calculated for impurity band; ${ }^{[8]}$ Calculated for trivial quantum well states; ${ }^{[9]}$ Carriers were majority $p$-type.

Finally, dielectric $\mathrm{SiO}_{2} / \mathrm{Si}$ substrates have been widely used to back gate $\mathrm{Bi}_{2} \mathrm{Se}_{3}$ flakes [90-92], prompting many attempts to directly grow on these substrates [73,74,93]. Although the amorphous nature of $\mathrm{SiO}_{2} / \mathrm{Si}$ would hinder traditional $\mathrm{MBE}$ growth, $\mathrm{Bi}_{2} \mathrm{Se}_{3}$ can still be grown by taking advantage of van der Waals epitaxy. Like silicon substrates, the $\mathrm{SiO}_{2}$ surface has dangling bonds which must be passivated before growth, usually through an initial exposure to a selenium flux. By using a selenium capping layer to protect the film, a sheet density of $\sim 1.5 \pm 0.04 \times 10^{13} / \mathrm{cm}^{2}$ at low temperatures was 
reported, implying the Fermi level is close to the edge of the conduction band. More importantly, a carrier concentration as low as $\sim 3.5 \times 10^{12} / \mathrm{cm}^{2}$ was achieved by applying a gate voltage of $-170 \mathrm{~V}$. A large enhancement of the peak resistance and the saturation of the sheet density suggest that this gate voltage fully depleted the bulk carriers and transport properties are now dominated by the topological surface states [74]. Controllable switching between dominating bulk or surface states is an important step toward real device applications.

\subsubsection{Cracking Source}

As discussed in Section 2.1.1, traditional K-cell selenium sources evaporate large molecules which are inefficiently incorporated into the films during growth, necessitating large selenium to bismuth ratios to create high quality films. Using a cracking source helps to overcome this problem by using a second heating zone held much hotter than the bulk evaporation zone or through the use of a radio-frequency cracker [94,95]. The cooler bulk evaporation zone is used to control the flux, while the large molecules that evaporate from the bulk are thermally cracked into monomers, dimers, and trimers in the cracking zone. These small molecules can be incorporated much more readily into the films, allowing Se:Bi ratios as low as 4:1 to be used while still achieving electrical properties comparable to samples grown via K-cell. While traditionally-grown films are prone to electrical aging effects, films grown with a cracker source have been demonstrated to maintain their electrical properties over a span of 60 days [62]. Better incorporation of selenium during growth is theorized to result in a smaller density of selenium vacancies, prohibiting oxygen from diffusing into the film as readily as in conventionally grown films.

\section{2. $\mathrm{Bi}_{2} \mathrm{Te}_{3}$}

Unlike the case of $\mathrm{Bi}_{2} \mathrm{Se}_{3}$, most growths of $\mathrm{Bi}_{2} \mathrm{Te}_{3}$ have been conducted on $\mathrm{Si}(111)$ substrates [83,96-100]. As discussed in Section 2.1.4, silicon substrates have dangling bonds which must be satisfied before growth can occur. As shown by Borisova et al. [41], these bonds can be terminated using a monolayer of Te upon which $\mathrm{Bi}_{2} \mathrm{Te}_{3}$ can nucleate in one of six possible orientations. The van der Waals bonding between the Te monolayer used to passivate the silicon substrate and the $\mathrm{Bi}_{2} \mathrm{Te}_{3}$ overlayer leads to a fully relaxed film within the first or second monolayer. In Situ x-ray scattering measurements by Liu et al. corroborate this finding and show the formation of a Te buffer layer in Te rich growth conditions even when the surface was not purposefully passivated [101]. Growth begins by the formation of many triangular islands which are only weakly bonded to the surface and are thus able to laterally diffuse along the surface. As film thickness increases, these islands coalesce until the substrate is completely covered, at which point the growth proceeds in a step flow mode, resulting in a similar pyramid structure as in $\mathrm{Bi}_{2} \mathrm{Se}_{3}$. This abrupt change in growth mode suggests that the diffusion length of adatoms is much larger on a completed QL than on the substrate. Much as in $\mathrm{Bi}_{2} \mathrm{Se}_{3}$ growths, growth of a high quality first QL is perhaps the most important factor in producing good films. Growing via van der Waals epitaxy allow for the use of substrates with large lattice mismatches, however controlling the initial nucleation is vital for reduction of defects and creation of an interface capable of supporting topological states. A counterintuitive advantage of silicon substrates is therefore their dangling bonds, which can be passivated by a tellurium monolayer, producing a surface that will support the growth of high-quality $\mathrm{Bi}_{2} \mathrm{Te}_{3}$.

If the substrate chosen does not have dangling bonds that can be satisfied with a Te monolayer, a two-step growth can be used to improve the interface at the substrate. High-quality topological insulators have been demonstrated on both sapphire [102,103] and $\mathrm{SrTiO}_{3}[104]$ using a two-step growth method. A nucleation layer is first deposited at a low substrate temperature ( 190C) and then slowly annealed to the higher growth temperature ( 230C), after which the rest of the film is deposited. After growth, the film is annealed at the growth temperature for an additional 30 minutes. This method resulted in films with a flatter morphology and reduced 3D growth defects than single-step TI growths. High-quality films have been grown on a number of different substrates including GaAs(001) [63], 
GaAs(111)B [36], GaN [105], graphene [65], amorphous fused silica [106], and mica (110) [86,107]. It is possible that adapting the two-step growth method will facilitate bulk insulating $\mathrm{Bi}_{2} \mathrm{Te}_{3}$ films on a wide variety of substrates.

Several studies of $\mathrm{Bi}_{2} \mathrm{Te}_{3}$ grown on $\mathrm{BaF}_{2}[80,108]$ have reported that small $\mathrm{Te} / \mathrm{Bi} \mathrm{BEP}$ ratios during growth led to the formation of bismuth bilayers between QLs, resulting in either the BiTe or $\mathrm{Bi}_{4} \mathrm{Te}_{3}$ phases in addition to or in place of the desired $\mathrm{Bi}_{2} \mathrm{Te}_{3}$ TI phase. Both alternate phases have considerably lower mobilities and higher carrier concentrations than $\mathrm{Bi}_{2} \mathrm{Te}_{3}$. In addition, neither phase shows evidence of the TI surface states. It is, therefore, extremely important to ensure the correct phase has been grown when studying these materials. The formation of alternate phases is most likely due to growth conditions with a deficit of tellurium. Fulop et al [81] found that a beam equivalent pressure ratio below 17 favored the growth of $\mathrm{Bi}_{4} \mathrm{Te}_{3}$, though this growth was not conducted using a cracking source. When Steiner et al [85] studied $\mathrm{Bi}_{2} \mathrm{Te}_{3-\delta}$ (where $\delta$ is the Te deficit) they found that $\delta$ close to 0 produced the most uniform quintuple layer steps despite good streaky reflection high energy electron diffraction (RHEED) being present for $\delta$ from 1 to 0 , as shown in Figure 8 . Therefore, RHEED may not be a reliable metric for achieving the correct composition. In addition, it is best to err on the tellurium-rich side of the phase diagram to insure the best film growth.
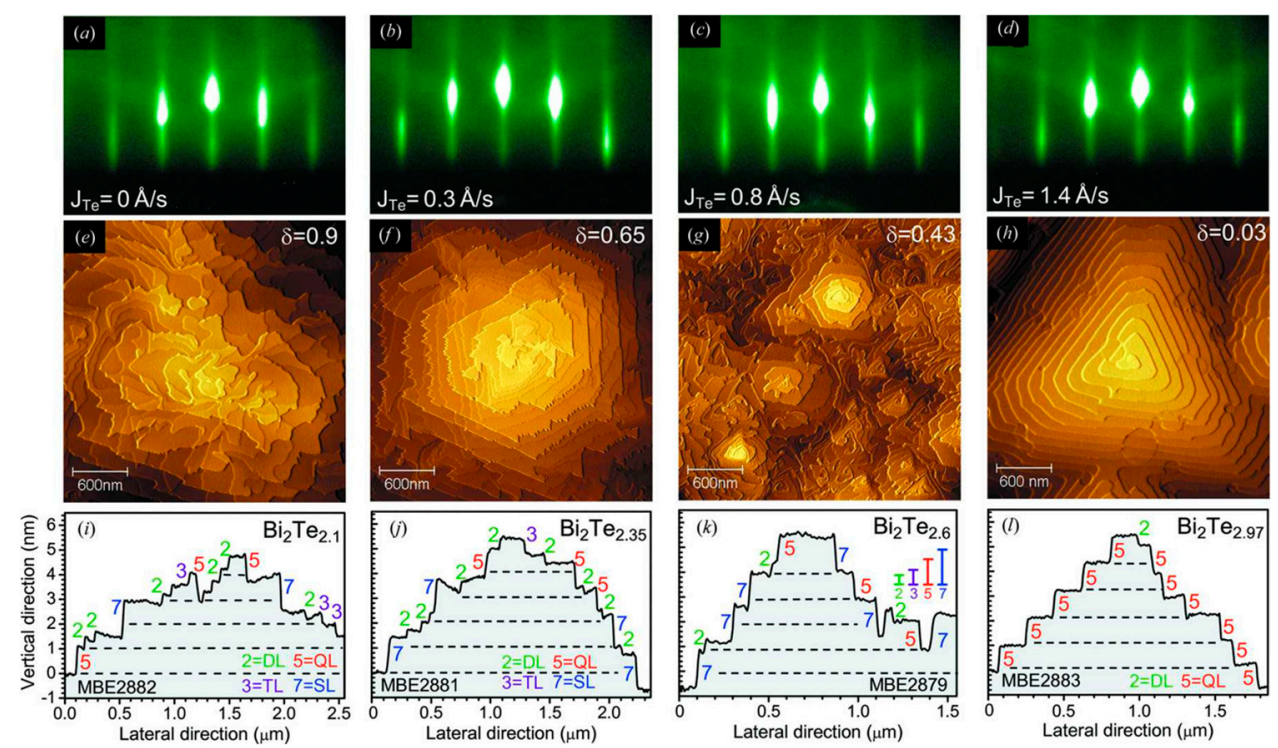

Figure 8. (a-d) RHEED patterns for $\mathrm{Bi}_{2} \mathrm{Te}_{3}$ growth with varying Te flux as indicated. (e-h) AFM images corresponding to the $\mathrm{Bi}_{2} \mathrm{Te}_{3}$ films grown with the parameters in panels (a-d). (i-l) Step height measurements for the $\mathrm{Bi}_{2} \mathrm{Te}_{3}$ films indicating double layers (DL), triple layers (TL), quintuple layers (QL), and septuple layers (SL) Reproduced with permission from Steiner et al., Journal of Applied Crystallography; published by the International Union of Crystallography, 2014 [85].

$\mathrm{Li}$ et al. report that the ideal condition for growing low carrier density $\mathrm{Bi}_{2} \mathrm{Te}_{3}$ thin films is a Te-rich growth environment where the bismuth Knudsen cell temperature is greater than the silicon substrate temperature which is greater than or equal to the tellurium Knudsen cell temperature $\left(\mathrm{T}_{\mathrm{bi}}>\mathrm{T}_{\mathrm{Si}} \geq \mathrm{T}_{\mathrm{Te}}\right)$ [99]. Keeping the substrate temperature equal to or above the tellurium cell temperature insures that $\mathrm{Te}_{2}$ molecules do not stick to the growth surface and film growth only occurs in the presence of a Bi flux. With the right growth conditions, carrier densities of $\sim 10^{12} \mathrm{~cm}^{-2}$ and mobilities of $4600 \mathrm{~cm}^{2} /$ Vs have been achieved, as calculated from ARPES data [51].

Finally, Wang et al [109] demonstrated that it is possible to transition from $n$-type to $p$-type doped films by varying substrate temperature. Using a silicon substrate and a growth temperature below $580 \mathrm{~K}$, films were n-type doped. Substrate temperatures between $580 \mathrm{~K}$ and $620 \mathrm{~K}$ produced relatively insulating films, while films grown above $620 \mathrm{~K}$ were $p$-type. In all cases, the carrier type was 
determined by monitoring the position of the Fermi energy with respect to the Dirac point through ARPES measurements performed in vacuum; no electrical measurements were performed. At high temperatures, the growth regime is step flow. Tellurium adatoms will have high mobility on the growth surface, increasing the probability of two adatoms combining to from $\mathrm{Te}_{2}$ and outgassing from the films. This results in a Te poor growth environment where Bi-on-Te antisite defects (acceptors) have a high probability of forming. At lower substrate temperatures the growth regime changes to layer by layer, as demonstrated by the presence of RHEED oscillations, and Te-on-Bi (donor) becomes the primary defect. The ability to control the transition from $p$-type to $n$-type films without the introduction of dopants is extremely useful for future device applications.

\section{3. $\mathrm{Sb}_{2} \mathrm{Te}_{3}$}

MBE-grown $\mathrm{Sb}_{2} \mathrm{Te}_{3}$ has not been as widely studied as either $\mathrm{Bi}_{2} \mathrm{Se}_{3}$ or $\mathrm{Bi}_{2} \mathrm{Te}_{3}$ and is most extensively studied as part of a ternary compound or heterostructure. As discussed Sections 3 and 4 , the intrinsic $p$-type doping of $\mathrm{Sb}_{2} \mathrm{Te}_{3}$ makes it an ideal candidate for alloying with $n$-type $\mathrm{Bi}_{2} \mathrm{Se}_{3}$ or $\mathrm{Bi}_{2} \mathrm{Te}_{3}$ to create net undoped films or for use in heterostructures to create $p-n$ junctions. The reported ideal growth parameters for $\mathrm{Sb}_{2} \mathrm{Te}_{3}$ vary widely. Growth rates range from $0.2-2 \mathrm{QL} / \mathrm{min}$, substrate temperatures from $200-320^{\circ} \mathrm{C}$, and Te:Sb flux ratios from 2:1 to 20:1. Successful growths have been reported on many substrates including CdTe(111)B [88], graphene [110], sapphire (0001) [111], $\mathrm{SiO}_{2}$ [79], prestructured $\mathrm{Si}(111) \mathrm{SOI}$ [82], and vicinal GaAs (111) (both A and B terminated) [89]. Where available, the electrical properties for each substrate are listed in Table 1. Bulk insulating $\mathrm{Sb}_{2} \mathrm{Te}_{3}$ has been demonstrated on $\mathrm{Si}(111) 7 \times 7$ substrates with robust TI surfaces states in films as thin as $6 \mathrm{QL}$ [52]. While $\mathrm{Bi}_{2} \mathrm{Se}_{3}$ requires a minimum of $6 \mathrm{QL}$ to display $\mathrm{TI}$ behavior, $\mathrm{Sb}_{2} \mathrm{Te}_{3}$ requires only $5 \mathrm{QL}$ to form gapless surface states [52].

While the ideal growth parameters are still being debated, there have been several studies on the effect of growth parameters on defect types. Using scanning tunneling microscopy (STM) in conjunction with density functional theory (DFT) calculations, Jiang et al [110] studied vacancy and antisite defects in $\mathrm{Sb}_{2} \mathrm{Te}_{3}$. These STM images are shown in Figure 9. They found that $\mathrm{Sb}$ vacancies are the primary source of doping for films grown at temperatures below $\sim 20{ }^{\circ} \mathrm{C}$. Unlike the case of $\mathrm{Bi}_{2} \mathrm{Se}_{3}$ or $\mathrm{Bi}_{2} \mathrm{Te}_{3}$, where $\mathrm{Bi}$ exists mostly in its atomic form, $\mathrm{Sb}$ exists mostly as a tetramer $\left(\mathrm{Sb}_{4}\right)$ if a cracking source is not used. Due to its low mobility, $\mathrm{Sb}$ tends to form clusters on the growth surface. At low growth temperatures, this mobility is further reduced and Te is less likely to reevaporate, leading to Te-rich conditions and an increase in $\mathrm{Sb}$ vacancies. At higher temperatures, $\mathrm{Sb}_{\mathrm{Te}}$ antisite defects on the outer Te sites become the dominant defect. Both defects types are acceptors, leading to the characteristic p-type doping observed in these films. Carrier concentration can be minimized by carefully selecting the substrate temperature during growth.

Kim et al [88] conducted a similar study by looking at the effect for Te:Sb flux ratio on the electronic properties and c-axis lattice constant of $\mathrm{Sb}_{2} \mathrm{Te}_{3}$ films. Bulk $\mathrm{Sb}_{2} \mathrm{Te}_{3}$ has a lattice constant of $30.458 \AA$. In thin films at flux ratios below 3:1, the lattice constant varies from 30.572 to $30.385 \AA$, while above 3:1, it decreases to between 30.385 to $30.404 \AA$. This can be explained by a switch from $\mathrm{Te}_{\mathrm{Sb}}$ to $\mathrm{Sb}_{\mathrm{Te}}$ antisite defects. $\mathrm{Sb}$ is a larger atom than $\mathrm{Te}$, so when it occupies a Te site, the lattice constant will increase to accommodate it. When $\mathrm{Te}$ on $\mathrm{Sb}$ defects start to dominate, the lattice constant decreases in response to the smaller atoms. Room temperature Hall measurements reveal the best electrical properties at a flux ratio of 3.6:1. Here the mobility has its maximum value of $279 \mathrm{~cm}^{2} \cdot \mathrm{V}^{-1} \cdot \mathrm{s}^{-1}$ and the 3D carrier concentration has its minimum value of $7.48 \times 10^{18} \mathrm{~cm}^{-3}$. Both of these studies highlight the importance of understanding defect formation as a guide to finding the best growth parameters. 

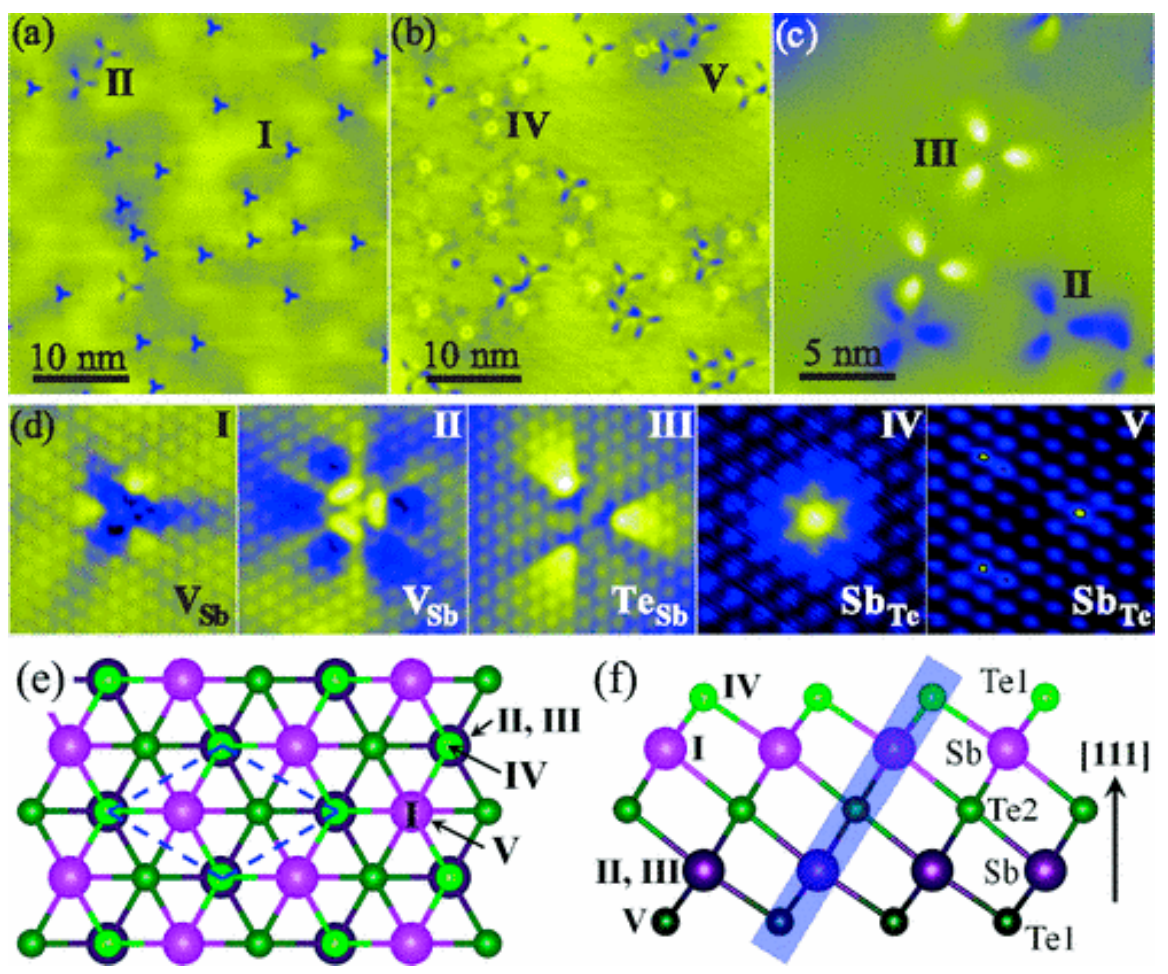

Figure 9. (a)-(c) Large-area STM images showing various types of defects in $\mathrm{Sb}_{2} \mathrm{Te}_{3}$, labeled from I to $\mathrm{V}$ with tunneling voltages of (a) $1.0 \mathrm{~V}, 50 \mathrm{pA}$; (b) $1.0 \mathrm{~V}, 50 \mathrm{pA}$; and (c) $0.4 \mathrm{~V}, 50 \mathrm{pA}$. (d) High-resolution STM images of defects labeled in (a)-(c) with tunneling conditions: (I) $0.2 \mathrm{~V}, 100$ pA; (II) $0.1 \mathrm{~V}, 100$ pA; (III) $0.2 \mathrm{~V}, 100 \mathrm{pA}$; (IV) $-0.5 \mathrm{~V}, 50 \mathrm{pA}$; and (V) -1.0 V, $50 \mathrm{pA}$. (e),(f) Schematic drawings of $\mathrm{Sb}_{2} \mathrm{Te}_{3}$ (111) crystal structure showing positions of the defects. Te and $\mathrm{Sb}$ atoms are denoted by small (green) and large (pink) spheres, respectively. Note that, looking from the top, I is above V and IV is above II and III. Reproduced with permission from Jiang et al., Physical Review Letters; published by the American Physical Society, 2012 [110].

\subsection{A Discussion on Carrier Density Determination}

Many of the most interesting applications for topological insulator films are in electronic devices. This necessitates films that exhibit conductivity only through the surface states with few to no trivial carriers and a high mobility of the topological carriers. Unfortunately, many reports on the quality of TI films show only ARPES data, from which the authors extract a variety of information such as the position of the Fermi energy with respect to the Dirac point as well as the overall carrier density and mobility. Many of these ARPES measurements are performed in vacuum immediately following growth or on freshly-cleaved surfaces. While APRES is an excellent technique for characterizing the surface band structure of TI films, it is our opinion that ARPES measurements are of limited utility for determining the electrical quality of TI films. ARPES is inherently a surface-sensitive technique and generally only samples the first few layers of any material. This is, of course, quite useful for understanding the properties of the surfaces of TI films including the dispersion of the topological states, the presence or absence of a trivial band-bending 2DEG, and the position of the surface Fermi energy. However, this small penetration depth means that ARPES measurements are not able to probe the bulk behavior of a material. When discussing electrical conductivity, understanding the behavior of the bulk of the sample is crucial to understanding the overall properties. In this regard, traditional Hall measurements provide a much clearer picture of the carrier density and mobility in the film. High-field Schubnikov-de Haas measurements and low-field Hall measurement using a parallel conduction model have also been used to good effect to separate electrical contributions from the various conducting channels in TI films and crystals [112-114]. In addition, electrical measurements 
tend to be performed after exposure to air, giving a measurement that is more relevant to those wishing to create electronic devices based on TIs. In Table 1 we therefore put more emphasis on carrier density and mobility reports as determined using electrical measurements than those determined from ARPES analyses. For a comprehensive discussion of the electrical properties of TI films, including the role of surface accumulation and depletion layers, the reader is referred to reference [115].

\section{Ternary Materials (E.G. $\left.\mathrm{Bi}_{2}\left(\mathrm{Se}_{1-\mathrm{x}} \mathrm{Te}_{\mathrm{x}}\right)_{3},\left(\mathrm{Bi}_{\mathrm{x}} \mathrm{Sb}_{1-\mathrm{x}}\right)_{2} \mathrm{Te}_{3}\right)$}

MBE-grown binary TIs have been widely explored, but the ideal bulk-insulating state remains difficult to achieve. Recently, a variety of studies on ternary compounds $\mathrm{Bi}_{2}\left(\mathrm{Te}_{\mathrm{x}} \mathrm{Se}_{1-\mathrm{x}}\right)_{3}$ and $\left(\mathrm{Bi}_{\mathrm{x}} \mathrm{Sb}_{1-\mathrm{x}}\right)_{2} \mathrm{Te}_{3}$ have been performed in an attempt to further reduce the bulk conductance of TI films

Compared with $\mathrm{Bi}_{2} \mathrm{Se}_{3}$ or $\mathrm{Bi}_{2} \mathrm{Te}_{3}, \mathrm{Bi}_{2} \mathrm{Te}_{2} \mathrm{Se}$ is predicted to be much more bulk-insulating due to its -Te-Bi-Se-Bi-Te- quintuple unit structures. It not only limits the formation of Se vacancies but also suppresses the $\mathrm{Bi} / \mathrm{Te}$ antisite defects [116]. $\mathrm{Bi}_{2} \mathrm{Te}_{2} \mathrm{Se}$ single crystals [117] and nanostructures [118] have already been widely explored, but reports on $\mathrm{MBE}$ growth of $\mathrm{Bi}_{2}\left(\mathrm{Te}_{\mathrm{x}} \mathrm{Se}_{1-\mathrm{x}}\right)_{3}$ alloys are still very limited. Y. Tung et al. [116] systematically studied the growth conditions of $\mathrm{Bi}_{2}\left(\mathrm{Te}_{\mathrm{x}} \mathrm{Se}_{1-\mathrm{x}}\right)_{3}$ in an $\mathrm{MBE}$ system. They successfully grew $\mathrm{Bi}_{2}\left(\mathrm{Te}_{\mathrm{x}} \mathrm{Se}_{1-\mathrm{x}}\right)_{3}$ on a sapphire substrate with a substrate temperature at $290{ }^{\circ} \mathrm{C}$. The composition was tuned by varying the Se:Te flux ratio. The ARPES data clearly indicated that the Fermi level moved downward to the bottom of the conduction band at the composition around $\mathrm{Bi}_{2} \mathrm{Te}_{2} \mathrm{Se}$. Their study supports the idea of reducing bulk carrier density by growing $\mathrm{Bi}_{2}\left(\mathrm{Te}_{\mathrm{x}} \mathrm{Se}_{1-\mathrm{x}}\right)_{3}$ alloys. However, no electrical measurements were performed, making it difficult to determine the bulk carrier density in these films. Despite the difficulty in growing, it is still possible to make more improvements based on this work. Choosing a more lattice matched substrate to reduce defects, or controlling the growth conditions more carefully are both possible ways to make further progress.

According to the band structure of pure $\mathrm{Bi}_{2} \mathrm{Te}_{3}$ and $\mathrm{Sb}_{2} \mathrm{Te}_{3}$ shown in Figure $10, \mathrm{Bi}_{2} \mathrm{Te}_{3}$ is $n$-type doped due to Te vacancies while $\mathrm{Sb}_{2} \mathrm{Te}_{3}$ is $p$-type doped due to $\mathrm{Sb} / \mathrm{Te}$ antisite defects. Therefore, it may be possible to tune the bulk carrier density and the position of the Fermi level by alloying the two compounds. Among the reports of $\left(\mathrm{Bi}_{\mathrm{x}} \mathrm{Sb}_{1-\mathrm{x}}\right)_{2} \mathrm{Te}_{3}$, the tuning of the Dirac point with composition was widely observed, but the exact composition where the carrier density was minimized is still under debate. Zhang et al. [119] engineered the band structure of the TI films by the MBE growth of $\left(\mathrm{Bi}_{\mathrm{x}} \mathrm{Sb}_{1-\mathrm{x}}\right)_{2} \mathrm{Te}_{3}$ alloys on sapphire substrates. The ARPES data indicated that the Fermi energy moved across the Dirac point as the Sb content was increased. The minimum bulk carrier sheet density was $1.4 \times 10^{12} \mathrm{~cm}^{-2}$ obtained at $\mathrm{x}=0.96$. J. Kellner et al. [120] reported that among their films grown on highly doped $\mathrm{Si}(111)$ substrates, the Fermi level crosses the Dirac point at $\mathrm{x}=0.94$. X. He et al. [121] reported $\mathrm{MBE}$ grown $\left(\mathrm{Bi}_{\mathrm{x}} \mathrm{Sb}_{1-\mathrm{x}}\right)_{2} \mathrm{Te}_{3}$ on $\mathrm{SrTiO}_{3}$ substrates. In their work, a sheet density as low as $3 \times 10^{12} \mathrm{~cm}^{-2}$ was obtained at around $\mathrm{x}=0.5$. Similar to their result, an Sb content of 0.47 was found to minimize the bulk conductance in a study on the surface spin polarizing behavior of $\left(\mathrm{Bi}_{\mathrm{x}} \mathrm{Sb}_{1-\mathrm{x}}\right)_{2} \mathrm{Te}_{3}$ grown on GaAs (111)B substrates [122]. C. Weyrich et al. [123] grew $\left(\mathrm{Bi}_{\mathrm{x}} \mathrm{Sb}_{1-\mathrm{x}}\right)_{2} \mathrm{Te}_{3}$ with various $\mathrm{Sb}$ content on $\mathrm{Si}(111)$ substrates. They reported the lowest sheet carrier density of $5 \times 10^{12} \mathrm{~cm}^{-2}$ with an $\mathrm{Sb}$ content of 0.42 . There clearly exists a dispute on the critical $\mathrm{Sb}$ content which is typically found to be either around 0.5 or around 0.9 . This disagreement may be attributed to a difference in growth conditions or substrate choice, but further research is required to consistently obtain bulk insulating TI films. However, the existing data clearly shows that alloying TI materials can result in improved film properties and shows one possible way of obtaining the bulk insulating materials needed for many device applications. The ability to precisely control flux ratios and growth dynamics make MBE an excellent technique for growing these high quality films. 
a

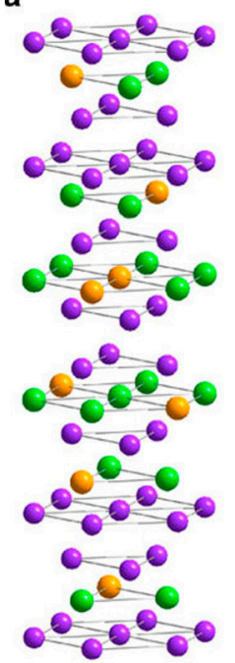

b

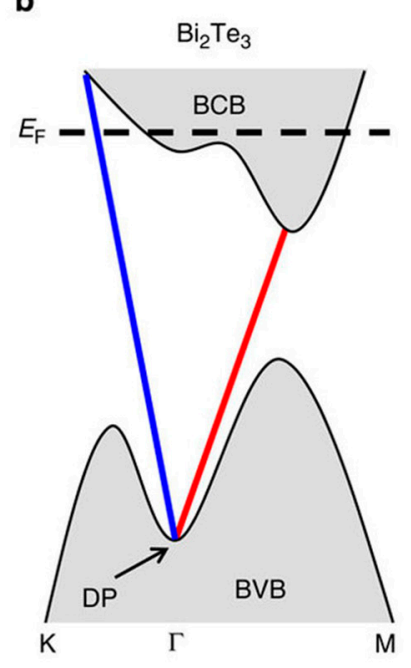

c

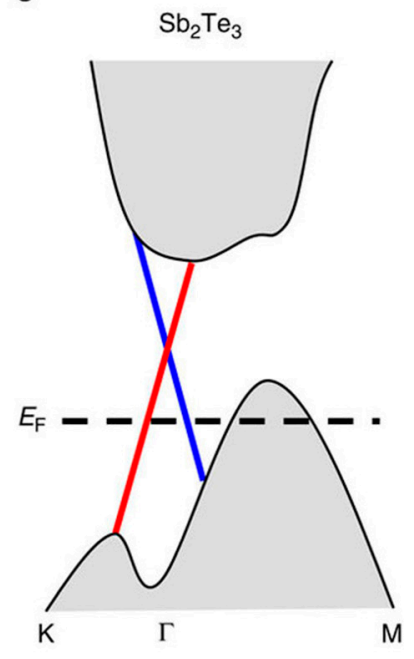

Figure 10. (a) Crystal structure of $\left(\mathrm{Bi}_{\mathrm{x}} \mathrm{Sb}_{1-\mathrm{x}}\right)_{2} \mathrm{Te}_{3}$ alloy. $\mathrm{Bi}_{2} \mathrm{Te}_{3}$ tends to have a Fermi level above the Dirac point as shown by the band structure diagram in (b) while $\mathrm{Sb}_{2} \mathrm{Te}_{3}$ tends to have a Fermi level below the Dirac point as shown by the band structure diagram in (c). Alloys are predicted to have a Fermi level tunable across the Dirac point. Reproduced with permission from Zhang et al., Nature Communications; published by Nature Publishing Group, 2011 [119].

\section{Heterostructures and Superlattices}

MBE is also a good method to grow layered structures such as heterostructures and superlattices. Heterostructures include any structure with two or more dissimilar crystalline materials with sharp interfaces between them. Superlattices are periodic structures of two or more material layers. By controlling the material composition, layer thickness, or doping densities of each layer, the electronic and optical properties of the whole structure can be modified. For heterostructures and superlattices that include TI components, the unique surface states of the TI layers generate many interesting phenomena at the interfaces. Recently, there have been a variety of theoretical calculations and experimental realizations of heterostructures or superlattices that combine TIs with other kinds of materials. In this section, we will discuss the progress in TI heterostructure and superlattices grown by MBE.

As previously discussed in Section 3, the alloying of p-type and n-type binary topological insulators can result in samples with a reduced bulk conductivity. In addition to growing ternary alloys, topological insulator $p$ - $n$ junctions have also been grown, typically using the binary compounds $\mathrm{Sb}_{2} \mathrm{Te}_{3} / \mathrm{Bi}_{2} \mathrm{Te}_{3} . \mathrm{Sb}_{2} \mathrm{Te}_{3}$ tends to be p-type doped due to $\mathrm{Sb} / \mathrm{Te}$ antisite defects, while $\mathrm{Bi}_{2} \mathrm{Te}_{3}$ tends to be n-type doped due to Te vacancies. Zeng et al. [89] grew $\mathrm{Bi}_{2} \mathrm{Te}_{3}$ and $\mathrm{Sb}_{2} \mathrm{Te}_{3}$ on $\mathrm{GaAs}$ (111) substrates successfully and pointed out the possibility to grow an $\mathrm{Sb}_{2} \mathrm{Te}_{3} / \mathrm{Bi}_{2} \mathrm{Te}_{3} \mathrm{p}-\mathrm{n}$ junction. Their work demonstrated that non-vincinal GaAs substrates produce higher quality $\mathrm{Q}_{2} \mathrm{Te}_{3}(\mathrm{Q}=\mathrm{Sb}, \mathrm{Bi})$ films than vicinal substrates. $\mathrm{Sb}_{2} \mathrm{Te}_{3} / \mathrm{Bi}_{2} \mathrm{Te}_{3}$ heterostructures on $\mathrm{Si}(111)$ substrates were first grown by Eschbach et al. [124]. By changing the thickness of $\mathrm{Sb}_{2} \mathrm{Te}_{3}$ layer, they were able to tune the chemical potential in the $\mathrm{Bi}_{2} \mathrm{Te}_{3}$ underlayer. ARPES data revealed that Dirac cone surface states still exist at the surface of $\mathrm{Sb}_{2} \mathrm{Te}_{3}$. Another group also reported $\mathrm{Sb}_{2} \mathrm{Te}_{3} / \mathrm{Bi}_{2} \mathrm{Te}_{3}$ heterostructures grown on $\mathrm{Si}(111)$ [125]. They found that ternary compounds formed at the interfaces due to $\mathrm{Sb} / \mathrm{Bi}$ diffusion between layers. The tunability of bulk carrier density in $\mathrm{Bi}_{2} \mathrm{Te}_{3}$ layer via variation of $\mathrm{Sb}_{2} \mathrm{Te}_{3}$ layer thickness was also demonstrated. MBE-grown $p-n$ junctions in TI films show great promise for studying novel quantum phenomena as well as potential applications in spintronics.

In addition to growing binary TI heterostructures, TI materials can also be grown in combination with other semiconductor or band insulator materials. Currently, the most promising band insulator material is $\mathrm{In}_{2} \mathrm{Se}_{3}$, which has the same QL structure as $\mathrm{Bi}_{2} \mathrm{Se}_{3}$, a relatively low lattice mismatch $(\sim 3.4 \%)$, 
and a reasonably large bandgap of $\sim 1.3 \mathrm{eV}$. A study on MBE grown $\mathrm{In}_{2} \mathrm{Se}_{3} / \mathrm{Bi}_{2} \mathrm{Se}_{3}$ superlattices revealed that by tuning the thickness of TI layer, the transport of the whole material could switch between 2D and 3D [126]. Wang et al. [127] grew $\mathrm{Bi}_{2} \mathrm{Se}_{3} / \mathrm{In}_{2} \mathrm{Se}_{3}$ superlattices on $\mathrm{Si}(111)$ substrates with good film uniformity and sharp interfaces. The TEM image in Figure 11 showed clear interfaces between layers of their samples. More importantly, they were able to switch $\mathrm{In}_{2} \mathrm{Se}_{3}$ and $\mathrm{Bi}_{2} \mathrm{Se}_{3}$ growth by switching In and Bi fluxes while the Se flux was kept unchanged. Brahlek et al. [128] developed a superlattice system by sandwiching a layer of $\mathrm{In}_{2} \mathrm{Se}_{3}$ between two layers of $\mathrm{Bi}_{2} \mathrm{Se}_{3}$. By varying the thickness of the interlayer, the coupling between the two TI layers could be tuned from strongly coupled to totally decoupled. Using $\left(\operatorname{In}_{\mathrm{x}} \mathrm{Bi}_{1-\mathrm{x}}\right)_{2} \mathrm{Se}_{3}$ as the interlayer gave similar results. By tuning the indium composition from 1 down to 0.3 , the coupling strength between bordering TI layers gradually increased at fixed interlayer thickness. These studies clearly revealed not only the eligibility of $\operatorname{In}_{2} \mathrm{Se}_{3}$ or $\left(\operatorname{In}_{\mathrm{x}} \mathrm{Bi}_{1-\mathrm{x}}\right)_{2} \mathrm{Se}_{3}$ as a buffer layer in $\mathrm{Bi}_{2} \mathrm{Se}_{3}$ growth, but also the tunability of transport properties.

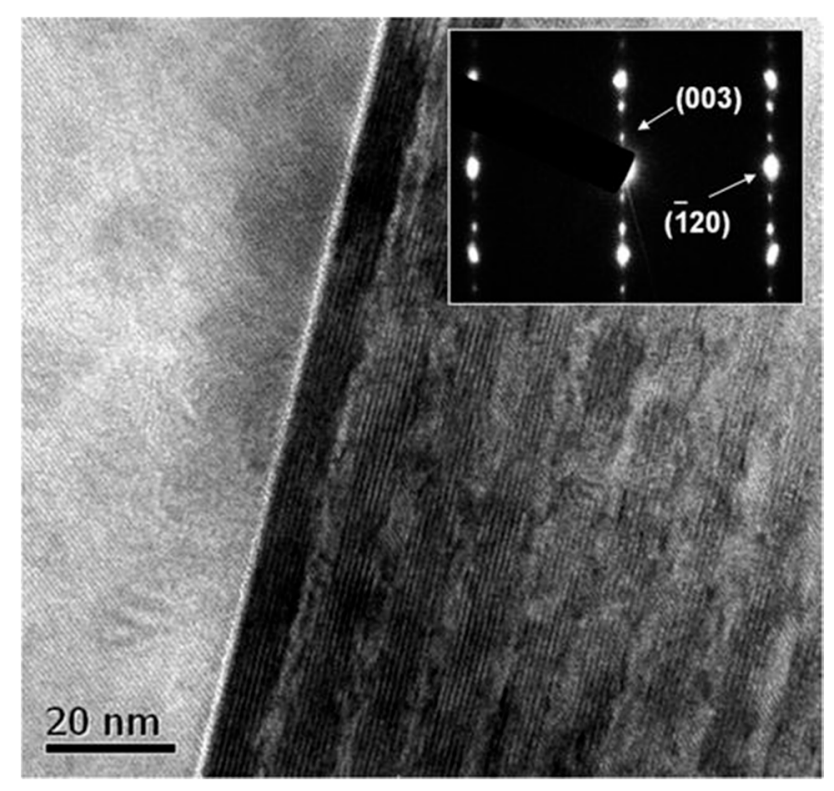

Figure 11. TEM image of a $3 \mathrm{~nm}-\mathrm{In}_{2} \mathrm{Se}_{3} / 7 \mathrm{~nm}-\mathrm{Bi}_{2} \mathrm{Se}_{3}$ superlattice sample. Inset: Transmission electron diffraction data of the same sample. Reproduced with permission from Wang et al., Applied Physics Letters; published by the American Institute of Physics, 2011 [127].

In addition to band insulators, II-VI semiconductor layers have also been grown in combination with TI materials. These structures are of interest since superlattices contain multiple buried topological/trivial interfaces, allowing the intrinsic transport behavior to be observed even after the film was removed from the MBE chamber. In addition, employing the II-VI family enables band structure engineering, resulting in devices with a variety of band gaps and band alignments between the TI layers and the normal materials. This material class also allows for the creation of multiple types of band alignment within the semiconductor layers, enabling unique functionality in the TI heterostructure device. The first attempt at a TI/II-VI heterostructure used ZnSe as the semiconductor layer due to its relatively small lattice mismatch with $\mathrm{Bi}_{2} \mathrm{Se}_{3}(\sim 3.2 \%)$ [129]. Unfortunately, a rough interface between the $\mathrm{Bi}_{2} \mathrm{Se}_{3}$ and the ZnSe was observed under high resolution SEM, making this heterostructure unsuitable for applications. This first attempt was followed by the growth of II-VI alloys by Zhiyi Chen et al. [130]. They grew $\mathrm{Zn}_{\mathrm{x}} \mathrm{Cd}_{1-\mathrm{x}} \mathrm{Se} / \mathrm{Bi}_{2} \mathrm{Se}_{3}$, and $\mathrm{Zn}_{\mathrm{x}} \mathrm{Cd}_{\mathrm{y}} \mathrm{Mg}_{1-\mathrm{x}-\mathrm{y}} \mathrm{Se} / \mathrm{Bi}_{2} \mathrm{Se}_{3}$ superlattices on sapphire substrates. Tuning the composition in the II-VI layer results in layers that are lattice matched to $\mathrm{Bi}_{2} \mathrm{Se}_{3}$, hence reducing the strain at the interface. They reported that $\mathrm{Zn}_{0.49} \mathrm{Cd}_{0.51} \mathrm{Se}$ and $\mathrm{Zn}_{0.23} \mathrm{Cd}_{0.25} \mathrm{Mg}_{0.52}$ Se layers had improved quality relative to $\mathrm{ZnSe}$. Another work by the same group reported that in $\mathrm{MBE}$ grown $\mathrm{Zn}_{0.49} \mathrm{Cd}_{0.51} \mathrm{Se} / \mathrm{Bi}_{2} \mathrm{Se}_{3}$ superlattices, a single topological Dirac cone 
per TI layer was realized [28]. Leveraging the wide range of band gaps and band alignments in II-VI materials lattice-matched to TIs opens the door to the creation of multifunctional devices.

In addition to the creation of heterostructures using traditional insulators and semiconductors, TIs can also be layered with magnetic insulators (MIs). In this case, the surface state of TI could become gapped due to the breaking of time reversal symmetry (TRS) through exchange coupling with the MI. Luo et al. [131] calculated a series of heterostructures of $\mathrm{Bi}_{2} \mathrm{Se}_{3}$ and magnetic or antiferromagnetic insulators. In their study, the $\mathrm{Bi}_{2} \mathrm{Se}_{3} / \mathrm{MnSe}$ heterostructure was concluded to be the most ideal for relatively strong exchange coupling and a simple surface band structure. An experimental study on $\mathrm{Bi}_{2} \mathrm{Se}_{3} / \mathrm{MnSe}$ heterostructures supported this prediction. Matetskiy et al [132] revealed that in the MBE-grown $\mathrm{Bi}_{2} \mathrm{Se}_{3} / \mathrm{MnSe}$ heterostructure, an energy gap of $90 \mathrm{meV}$ is observed at the TI surface state, possibly due to the breaking of TRS. More complicated materials have also been attempted, including a $\left(\mathrm{Bi}_{\mathrm{x}} \mathrm{Sb}_{1-\mathrm{x}}\right)_{2} \mathrm{Te}_{3} /$ yttrium iron garnet (YIG) heterostructure. This sample was made by directly growing $\left(\mathrm{Bi}_{\mathrm{x}} \mathrm{Sb}_{1-\mathrm{x}}\right)_{2} \mathrm{Te}_{3}$ onto a YIG substrate [133]. YIG was chosen as an under-layer because of its relatively large bulk band gap $(2.85 \mathrm{eV})$. The advantage of such a system is its tunability in the magnetic properties at the interface.

Newer materials, including 2D materials, have also been grown in proximity to TI materials. Chang et al [134] engineered the band structure of $\mathrm{Bi}_{2} \mathrm{Se}_{3}$ by growing another 2D material atop it. They investigated two types of structures: $\mathrm{Bi}_{2} \mathrm{Se}_{3}$ or $\mathrm{Sb}_{2} \mathrm{Te}_{3}$ grown on a graphene terminated $6 \mathrm{H}$-silicon carbide (0001) substrate covered by $1 \mathrm{QL}$ of $\mathrm{Bi}_{2} \mathrm{Te}_{3}$, and $\mathrm{Bi}_{2} \mathrm{Se}_{3}$ covered by 1 bilayer (BL) of $\mathrm{Bi}(111)$. ARPES data showed that both $\mathrm{Bi}_{2} \mathrm{Te}_{3} / \mathrm{Bi}_{2} \mathrm{Se}_{3}$ and $\mathrm{Bi}_{2} \mathrm{Te}_{3} / \mathrm{Sb}_{2} \mathrm{Te}_{3}$ showed similar surface states to $\mathrm{Bi}_{2} \mathrm{Te}_{3}$. This phenomenon can be understood by realizing that $\mathrm{Bi}_{2} \mathrm{Se}_{3}, \mathrm{Sb}_{2} \mathrm{Te}_{3}$, and $\mathrm{Bi}_{2} \mathrm{Te}_{3}$ all have the same $Z_{2}$ number, which determines the surface topology [135]. However, the band structure changed significantly when the $\mathrm{Bi}_{2} \mathrm{Se}_{3}$ film was covered by $\mathrm{BL} \mathrm{Bi}(111)$. ARPES data showed that the Dirac points from both $\mathrm{BL} \mathrm{Bi}(111)$ and $\mathrm{Bi}_{2} \mathrm{Se}_{3}$ film coexisted, but the band dispersion was significantly modified. Another work on MBE grown $\mathrm{BL} \mathrm{Bi}(111)$ atop $\mathrm{Bi}_{2} \mathrm{Te}_{3}$ heterostructures reported a shift of the Dirac point and a band bending effect at the $\mathrm{Bi}_{2} \mathrm{Te}_{3}$ and $\mathrm{Bi} \mathrm{BL}$ interface [136]. They proposed the band structure of the system, and demonstrated the possibility of building band engineering devices based on such a structure.

Finally, it is predicted to be possible to find Majorana fermions if superconductivity can be introduced to TI through the proximity effect. Mei-Xiao Wang et al. [137] prepared atomically-flat $\mathrm{Bi}_{2} \mathrm{Se}_{3}$ films using MBE on top of $2 \mathrm{H}-\mathrm{NbSe}_{2}(0001)$, which is an $s$-wave superconductor substrate. This heterostructure exhibited a superconducting gap at the $\mathrm{Bi}_{2} \mathrm{Se}_{3}$ surface. A detailed ARPES study followed, indicating a deviation from idealized theoretical model in $\mathrm{Bi}_{2} \mathrm{Se}_{3} / \mathrm{NbSe}_{2}$ heterostructure due to the coexistence of multiple bands at the chemical potential [138]. $\mathrm{Bi}_{2} \mathrm{Te}_{3} / \mathrm{NbSe}_{2}$ heterostructures have also been reported $[139,140]$. These results showed that superconducting order was induced in the TI surface states through the proximity effect. In addition, evidence for a Majorana mode in a magnetic vortex in the $\mathrm{Bi}_{2} \mathrm{Se}_{3} / \mathrm{NbSe}_{3}$ heterostructure was observed. Su-Yang Xu et al. [141] reported epitaxially growing $\mathrm{Bi}_{2} \mathrm{Se}_{3}$ on a cuprate-superconductor $\mathrm{Bi}_{2} \mathrm{Sr}_{2} \mathrm{CaCu}_{2} \mathrm{O}_{8+\delta}$ (BSCCO) substrate. The electronic structure near the Fermi level of the system was studied. Their ARPES data provided evidence for the coexistence of two crystal phases in the film. However, despite the crystalline nature of the film, they were unable to observe the superconducting proximity effect in the TI film. This absence of proximity effect was confirmed by another study on MBE grown $\mathrm{Bi}_{2} \mathrm{Se}_{3} / \mathrm{BSCCO}$ heterostructure [142]. The absence of proximity effect, as stated in both studies, could be possibly attributed to a small superconducting coherence length, the presence of the topological surface state, and the different symmetries at the interface.

\section{Conclusions}

In conclusion, $\mathrm{MBE}$ is an excellent technique for the growth of TI thin films, heterostructures, and superlattices. The growth techniques used to obtain thin films of $\mathrm{Bi}_{2} \mathrm{Se}_{3}, \mathrm{Bi}_{2} \mathrm{Te}_{3}, \mathrm{Sb}_{2} \mathrm{Te}_{3}$, and alloys have been discussed in detail in this review, including the electrical properties that result when the 
substrate or growth conditions are changed. Although TIs are theorized to grow by van der Waals epitaxy, we find that there is significant evidence suggesting that the substrate strongly influences the quality of the resulting TI film. Choosing more lattice-matched substrates, careful preparation of the substrate surface, and the use of buffer layers have all resulted in an improvement in TI film properties. We believe that further experimentation will result in high structural quality films with a simultaneous low bulk carrier density, suitable for device applications. In addition, MBE is perfectly suited for the growth of a variety of superlattices and heterostructures, which can lead to new physics and new devices. We therefore conclude that there is a bright future for the MBE growth of the $\mathrm{V}_{2} \mathrm{VI}_{3}$ topological insulator family.

Acknowledgments: Theresa P. Ginley acknowledges funding from the University of Delaware Research Foundation, Grant No. 15A00862. Yong Wang and Stephanie Law are partially supported by the U.S. Department of Energy, Office of Science, Office of Basic Energy Sciences, under Award Number DE-SC0016380.

Author Contributions: Theresa P. Ginley, Yong Wang and Stephanie Law all wrote the paper.

Conflicts of Interest: The authors declare no conflict of interest.

\section{References}

1. Chen, Y.L.; Analytis, J.G.; Chu, J.-H.; Liu, Z.K.; Mo, S.-K.; Qi, X.L.; Zhang, H.J.; Lu, D.H.; Dai, X.; Fang, Z.; et al. Experimental realization of a three-dimensional topological insulator, $\mathrm{Bi}_{2} \mathrm{Te}_{3}$. Science 2009, 325, $178-181$. [CrossRef] [PubMed]

2. Xia, Y.; Qian, D.; Hsieh, D.; Wray, L.; Pal, A.; Lin, H.; Bansil, A.; Grauer, D.; Hor, Y.S.; Cava, R.J.; et al. Observation of a large-gap topological-insulator class with a single Dirac cone on the surface. Nat. Phys. 2009, 5, 398-402. [CrossRef]

3. Hsieh, D.; Xia, Y.; Qian, D.; Wray, L.; Dil, J.H.; Meier, F.; Osterwalder, J.; Patthey, L.; Checkelsky, J.G.; Ong, N.P.; et al. A tunable topological insulator in the spin helical Dirac transport regime. Nature 2009, 460, 1101-1105. [CrossRef] [PubMed]

4. Hsieh, D.; Xia, Y.; Qian, D.; Wray, L.; Dil, J.H.; Osterwalder, J.; Patthey, L.; Fedorov, A.V.; Lin, H.; Bansil, A.; et al. Observation of Time-Reversal-Protected Single-Dirac-Cone Topological-Insulator States. Phys. Rev. Lett. 2009, 103, 146401. [CrossRef] [PubMed]

5. Zhang, H.; Liu, C.-X.; Qi, X.-L.; Dai, X.; Fang, Z.; Zhang, S.-C. Topological insulators in $\mathrm{Bi}_{2} \mathrm{Se}_{3}, \mathrm{Bi}_{2} \mathrm{Te}_{3}$ and $\mathrm{Sb}_{2} \mathrm{Te}_{3}$ with a single Dirac cone on the surface. Nat. Phys. 2009, 5, 438-442. [CrossRef]

6. Zhu, X.; Santos, L.; Howard, C.; Sankar, R.; Chou, F.C.; Chamon, C.; El-Batanouny, M. Electron-Phonon Coupling on the Surface of the Topological Insulator $\mathrm{Bi}_{2} \mathrm{Se}_{3}$ Determined from Surface-Phonon Dispersion Measurements. Phys. Rev. Lett. 2012, 108, 185501. [CrossRef] [PubMed]

7. Pan, Z.-H.; Fedorov, A.V.; Gardner, D.; Lee, Y.S.; Chu, S.; Valla, T. Measurement of an Exceptionally Weak Electron-Phonon Coupling on the Surface of the Topological Insulator $\mathrm{Bi}_{2} \mathrm{Se}_{3}$ Using Angle-Resolved Photoemission Spectroscopy. Phys. Rev. Lett. 2012, 108, 187001. [CrossRef] [PubMed]

8. Nemec, P.; Novák, V.; Sinova, J.; Jungwirth, T. Spin Hall Effect Transistor. Science 2010, 330, 1801-1804.

9. Appelbaum, I.; Drew, H.D.; Fuhrer, M.S.; Appelbaum, I.; Drew, H.D.; Fuhrer, M.S. Proposal for a topological plasmon spin rectifier. Appl. Phys. Lett. 2011, 98, 23103. [CrossRef]

10. Fu, L.; Kane, C. Superconducting Proximity Effect and Majorana Fermions at the Surface of a Topological Insulator. Phys. Rev. Lett. 2008, 100, 96407. [CrossRef] [PubMed]

11. Akhmerov, A.R.; Nilsson, J.; Beenakker, C.W.J. Electrically Detected Interferometry of Majorana Fermions in a Topological Insulator. Phys. Rev. Lett. 2009, 102, 216404. [CrossRef] [PubMed]

12. Hasan, M.Z.; Kane, C.L. Colloquium: Topological insulators. Rev. Mod. Phys. 2010, 82, 3045-3067. [CrossRef]

13. Bernevig, B.A.; Zhang, S. Quantum Spin Hall Effect. Phys. Rev. Lett. 2006, 96, 106802. [CrossRef] [PubMed]

14. Bernevig, B.A.; Hughes, T.L.; Zhang, S.-C. Quantum spin hall effect and topological phase transition in HgTe quantum wells. Science 2006, 314, 1757-1761. [CrossRef] [PubMed]

15. Fu, L.; Kane, C.L.; Mele, E.J. Topological Insulators in Three Dimensions. Phys. Rev. Lett. 2007, $98,106803$. [CrossRef] [PubMed]

16. Moore, J.E.; Balents, L. Topological invariants of time-reversal-invariant band structures. Phys. Rev. B 2007, 75, 121306(R). [CrossRef] 
17. Roy, R. Topological phases and the quantum spin Hall effect in three dimensions. Phys. Rev. B 2009, 79, 195322. [CrossRef]

18. Hsieh, D.; Qian, D.; Wray, L.; Xia, Y.; Hor, Y.S.; Cava, R.J.; Hasan, M.Z. A topological Dirac insulator in a quantum spin Hall phase. Nature 2008, 452, 970-974. [CrossRef] [PubMed]

19. Hsieh, D.; Xia, Y.; Wray, L.; Qian, D.; Pal, A.; Dil, J.H.; Osterwalder, J.; Meier, F.; Bihlmayer, G.; Kane, C.L.; et al. Observation of Unconventional Quantum Spin Textures in Topological Insulators. Science 2009, 323, 919-922. [CrossRef] [PubMed]

20. Moore, J.E. The birth of topological insulators. Nature 2010, 464, 194-198. [CrossRef] [PubMed]

21. Guo, Y.; Liu, Z.; Peng, H. A Roadmap for Controlled Production of Topological Insulator Nanostructures and Thin Films. Small 2015, 11, 3290-3305. [CrossRef] [PubMed]

22. Chang, C.; Zhang, J.; Feng, X.; Shen, J.; Zhang, Z.; Guo, M.; Li, K.; Ou, Y.; Wei, P.; Wang, L.; et al. Experimental Observation of the Quantum Anomalous Hall Effect in a Magnetic Topological Insulator. Science 2013, 340, 167-171. [CrossRef] [PubMed]

23. Qi, S.; Qiao, Z.; Deng, X.; Cubuk, E.D.; Chen, H.; Zhu, W.; Kaxiras, E.; Zhang, S.B.; Xu, X.; Zhang, Z. High-Temperature Quantum Anomalous Hall Effect in n-p Codoped Topological Insulators. Phys. Rev. Lett. 2016, 117, 056804. [CrossRef] [PubMed]

24. Chang, C.Z.; Zhang, J.; Liu, M.; Zhang, Z.; Feng, X.; Li, K.; Wang, L.L.; Chen, X.; Dai, X.; Fang, Z.; et al. Thin films of magnetically doped topological insulator with carrier-independent long-range ferromagnetic order. Adv. Mater. 2013, 25, 1065-1070. [CrossRef] [PubMed]

25. Chang, C.-Z.; Zhao, W.; Kim, D.Y.; Zhang, H.; Assaf, B.A.; Heiman, D.; Zhang, S.-C.; Liu, C.; Chan, M.H.W.; Moodera, J.S. High-precision realization of robust quantum anomalous Hall state in a hard ferromagnetic topological insulator. Nat. Mater. 2015, 14, 473-477. [CrossRef] [PubMed]

26. Kou, X.; Guo, S.T.; Fan, Y.; Pan, L.; Lang, M.; Jiang, Y.; Shao, Q.; Nie, T.; Murata, K.; Tang, J.; et al. Scale-invariant quantum anomalous hall effect in magnetic topological insulators beyond the two-dimensional limit. Phys. Rev. Lett. 2014, 113, 137201. [CrossRef] [PubMed]

27. Checkelsky, J.G.; Yoshimi, R.; Tsukazaki, A.; Takahashi, K.S.; Kozuka, Y.; Falson, J.; Kawasaki, M.; Tokura, Y. Trajectory of the anomalous Hall effect towards the quantized state in a ferromagnetic topological insulator. Nat. Phys. 2014, 10, 731-736. [CrossRef]

28. Chen, Z.; Zhao, L.; Park, K.; Garcia, T.A.; Tamargo, M.C.; Krusin-Elbaum, L. Robust Topological Interfaces and Charge Transfer in Epitaxial $\mathrm{Bi}_{2} \mathrm{Se}_{3} / \mathrm{II}-\mathrm{VI}$ Semiconductor Superlattices. Nano Lett. 2015, 15, 6365-6370. [CrossRef] [PubMed]

29. Bianchi, M.; Guan, D.; Bao, S.; Mi, J.; Iversen, B.B.; King, P.D.C.; Hofmann, P. Coexistence of the topological state and a two-dimensional electron gas on the surface of $\mathrm{Bi}_{2} \mathrm{Se}_{3}$. Nat. Commun. 2010, 1, 128. [CrossRef] [PubMed]

30. Koma, A.; Sunouchi, K.; Miyajima, T. Fabrication and characterization of heterostructures with subnanometer thickness. Microelectron. Eng. 1984, 2, 129-136. [CrossRef]

31. Koma, A. Van der Waals epitaxy-A new epitaxial growth method for a highly lattice-mismatched system. Thin Solid Films 1992, 216, 72-76. [CrossRef]

32. Momma, K.; Izumi, F. VESTA 3 for three-dimensional visualization of crystal, volumetric and morphology data. J. Appl. Crystallogr. 2011, 44, 1272-1276. [CrossRef]

33. Chang, C.-Z.; He, K.; Wang, L.-L.; Ma, X.-C.; Liu, M.-H.; Zhang, Z.-C.; Chen, X.; Wang, Y.-Y.; Xue, Q.-K. Growth of quantum well films of topological insulator $\mathrm{Bi}_{2} \mathrm{Se}_{3}$ on insulating substrate. SPIN 2011, 1, 21. [CrossRef]

34. Tarakina, N.V.; Schreyeck, S.; Luysberg, M.; Grauer, S.; Schumacher, C.; Karczewski, G.; Brunner, K.; Gould, C.; Buhmann, H.; Dunin-Borkowski, R.E.; et al. Suppressing Twin Formation in $\mathrm{Bi}_{2} \mathrm{Se}_{3}$ Thin Films. Adv. Mater. Interfaces 2014, 1, 1400134. [CrossRef]

35. Kampmeier, J.; Borisova, S.; Plucinski, L.; Luysberg, M.; Mussler, G.; Grutzmacher, D. Suppressing Twin Domains in Molecular Beam Epitaxy Grown $\mathrm{Bi}_{2} \mathrm{Te}_{3}$ Topological Insulator Thin Films. Cryst. Growth Des. 2015, 15, 390-394. [CrossRef]

36. Richardella, A.; Zhang, D.M.; Lee, J.S.; Koser, A.; Rench, D.W.; Yeats, A.L.; Buckley, B.B.; Awschalom, D.D.; Samarth, N. Coherent heteroepitaxy of $\mathrm{Bi}_{2} \mathrm{Se}_{3}$ on GaAs (111)B. Appl. Phys. Lett. 2010, 97, 262104. [CrossRef] 
37. Schreyeck, S.; Tarakina, N.V.; Karczewski, G.; Schumacher, C.; Borzenko, T.; Brüne, C.; Buhmann, H.; Gould, C.; Brunner, K.; Molenkamp, L.W.; et al. Molecular beam epitaxy of high structural quality $\mathrm{Bi}_{2} \mathrm{Se}_{3}$ on lattice matched InP(111) substrates. Appl. Phys. Lett. 2013, 102, 041914. [CrossRef]

38. Guo, X.; Xu, Z.J.; Liu, H.J.C.; Zhao, B.; Dai, X.Q.; He, H.T.; Wang, J.N.; Liu, H.J.C.; Ho, W.K.; Xie, M.H. Single domain $\mathrm{Bi}_{2} \mathrm{Se}_{3}$ films grown on InP(111)A by molecular-beam epitaxy. Appl. Phys. Lett. 2013, 102, 151604. [CrossRef]

39. He, L.; Xiu, F.; Wang, Y.; Fedorov, A.V.; Huang, G.; Kou, X.; Lang, M.; Beyermann, W.P.; Zou, J.; Wang, K.L. Epitaxial growth of $\mathrm{Bi}_{2} \mathrm{Se}_{3}$ topological insulator thin films on Si(111). J. Appl. Phys. 2011, 109, 103702. [CrossRef]

40. Bansal, N.; Kim, Y.S.; Edrey, E.; Brahlek, M.; Horibe, Y.; Iida, K.; Tanimura, M.; Li, G.-H.; Feng, T.; Lee, H.-D.; et al. Epitaxial growth of topological insulator $\mathrm{Bi}_{2} \mathrm{Se}_{3}$ film on $\mathrm{Si}(111)$ with atomically sharp interface. Thin Solid Films 2011, 520, 224-229. [CrossRef]

41. Borisova, S.; Krumrain, J.; Luysberg, M.; Mussler, G.; Grützmacher, D. Mode of Growth of Ultrathin Topological Insulator $\mathrm{Bi}_{2} \mathrm{Te}_{3}$ Films on $\mathrm{Si}(111)$ Substrates. Cryst. Growth Des. 2012, 12, 6098-6103. [CrossRef]

42. Wang, Z.Y.; Li, H.D.; Guo, X.; Ho, W.K.; Xie, M.H. Growth characteristics of topological insulator $\mathrm{Bi}_{2} \mathrm{Se}_{3}$ films on different substrates. J. Cryst. Growth 2011, 334, 96-102. [CrossRef]

43. Rathi, S.J.; Smith, D.J.; Drucker, J. Optimization of $\mathrm{In}_{2} \mathrm{Se}_{3} / \mathrm{Si}(111)$ Heteroepitaxy To Enable $\mathrm{Bi}_{2} \mathrm{Se}_{3} / \mathrm{In}_{2} \mathrm{Se}_{3}$ Bilayer Growth. Cryst. Growth Des. 2014, 14, 4617-4623. [CrossRef]

44. Koirala, N.; Brahlek, M.; Salehi, M.; Wu, L.; Dai, J.; Waugh, J.; Nummy, T.; Han, M.-G.; Moon, J.; Zhu, Y.; et al. Record Surface State Mobility and Quantum Hall Effect in Topological Insulator Thin Films via Interface Engineering. Nano Lett. 2015, 15, 8245-8249. [CrossRef] [PubMed]

45. Valdés Aguilar, R.; Wu, L.; Stier, A.V.; Bilbro, L.S.; Brahlek, M.; Bansal, N.; Oh, S.; Armitage, N.P. Aging and reduced bulk conductance in thin films of the topological insulator $\mathrm{Bi}_{2} \mathrm{Se}_{3}$. J. Appl. Phys. 2013, 113, 153702. [CrossRef]

46. Bianchi, M.; Hatch, R.C.; Mi, J.; Iversen, B.B.; Hofmann, P. Simultaneous quantization of bulk conduction and valence states through adsorption of nonmagnetic impurities on $\mathrm{Bi}_{2} \mathrm{Se}_{3}$. Phys. Rev. Lett. 2011, 107, 086802. [CrossRef] [PubMed]

47. King, P.D.C.; Hatch, R.C.; Bianchi, M.; Ovsyannikov, R.; Lupulescu, C.; Landolt, G.; Slomski, B.; Dil, J.H.; Guan, D.; Mi, J.L.; et al. Large Tunable Rashba Spin Splitting of a Two-Dimensional Electron Gas in $\mathrm{Bi}_{2} \mathrm{Se}_{3}$. Phys. Rev. Lett. 2011, 107, 096802. [CrossRef] [PubMed]

48. Chen, C.; He, S.; Weng, H.; Zhang, W.; Zhao, L.; Liu, H.; Jia, X.; Mou, D.; Liu, S.; He, J.; et al. Robustness of topological order and formation of quantum well states in topological insulators exposed to ambient environment. Proc. Natl. Acad. Sci. USA 2012, 109, 3694-3698. [CrossRef] [PubMed]

49. Benia, H.M.; Lin, C.; Kern, K.; Ast, C.R. Reactive Chemical Doping of the $\mathrm{Bi}_{2} \mathrm{Se}_{3}$ Topological Insulator. Phys. Rev. Lett. 2011, 107, 177602. [CrossRef] [PubMed]

50. Bianchi, M.; Hatch, R.C.; Guan, D.; Planke, T.; Mi, J.; Iversen, B.B.; Hofmann, P. The electronic structure of clean and adsorbate-covered $\mathrm{Bi}_{2} \mathrm{Se}_{3}$ : An angle-resolved photoemission study. Semicond. Sci. Technol. 2012, 27, 124001. [CrossRef]

51. Hoefer, K.; Becker, C.; Rata, D.; Swanson, J.; Thalmeier, P.; Tjeng, L.H. Intrinsic conduction through topological surface states of insulating $\mathrm{Bi}_{2} \mathrm{Te}_{3}$ epitaxial thin films. Proc. Natl. Acad. Sci. USA 2014, 111, 14979-14984. [CrossRef] [PubMed]

52. Wang, G.; Zhu, X.; Wen, J.; Chen, X.; He, K.; Wang, L.; Ma, X.; Liu, Y.; Dai, X.; Fang, Z.; et al. Atomically smooth ultrathin films of topological insulator $\mathrm{Sb}_{2} \mathrm{Te}_{3}$. Nano Res. 2010, 3, 874-880. [CrossRef]

53. Plucinski, L.; Herdt, A.; Fahrendorf, S.; Bihlmayer, G.; Mussler, G.; Döring, S.; Kampmeier, J.; Matthes, F.; Bürgler, D.E.; Grützmacher, D.; et al. Electronic structure, surface morphology, and topologically protected surface states of $\mathrm{Sb}_{2} \mathrm{Te}_{3}$ thin films grown on $\mathrm{Si}(111)$. J. Appl. Phys. 2013, 113, 053706. [CrossRef]

54. Pauly, C.; Bihlmayer, G.; Liebmann, M.; Grob, M.; Georgi, A.; Subramaniam, D.; Scholz, M.R.; Sánchez-Barriga, J.; Varykhalov, A.; Blügel, S.; et al. Probing two topological surface bands of $\mathrm{Sb}_{2} \mathrm{Te}_{3}$ by spin-polarized photoemission spectroscopy. Phys. Rev. B Condens. Matter Mater. Phys. 2012, 86, 235106. [CrossRef]

55. Seixas, L.; Abdalla, L.B.; Schmidt, T.M.; Fazzio, A.; Miwa, R.H. Topological states ruled by stacking faults in $\mathrm{Bi}_{2} \mathrm{Se}_{3}$ and $\mathrm{Bi}_{2} \mathrm{Te}_{3}$. J. Appl. Phys. 2013, 113, 023705. [CrossRef] 
56. Tarakina, N.V.; Schreyeck, S.; Borzenko, T.; Schumacher, C.; Karczewski, G.; Brunner, K.; Gould, C.; Buhmann, H.; Molenkamp, L.W. Comparative Study of the Microstructure of $\mathrm{Bi}_{2} \mathrm{Se}_{3}$ Thin Films Grown on Si(111) and InP(111) Substrates. Cryst. Growth Des. 2012, 12, 1913-1918. [CrossRef]

57. Li, H.D.; Wang, Z.Y.; Kan, X.; Guo, X.; He, H.T.; Wang, Z.; Wang, J.N.; Wong, T.L.; Wang, N.; Xie, M.H. The van der Waals epitaxy of $\mathrm{Bi}_{2} \mathrm{Se}_{3}$ on the vicinal $\mathrm{Si}(111)$ surface: An approach for preparing high-quality thin films of a topological insulator. New J. Phys. 2010, 12, 103038. [CrossRef]

58. Takagaki, Y.; Jenichen, B. Epitaxial growth of $\mathrm{Bi}_{2} \mathrm{Se}_{3}$ layers on $\mathrm{InP}$ substrates by hot wall epitaxy. Semicond. Sci. Technol. 2012, 27, 35015. [CrossRef]

59. Alpichshev, Z.; Biswas, R.R.; Balatsky, A.V.; Analytis, J.G.; Chu, J.-H.; Fisher, I.R.; Kapitulnik, A. STM Imaging of Impurity Resonances on $\mathrm{Bi}_{2} \mathrm{Se}_{3}$. Phys. Rev. Lett. 2012, 108, 206402. [CrossRef] [PubMed]

60. Analytis, J.G.; Chu, J.-H.; Chen, Y.; Corredor, F.; Mcdonald, R.D.; Shen, Z.X.; Fisher, I.R. Bulk Fermi surface coexistence with Dirac surface state in $\mathrm{Bi}_{2} \mathrm{Se}_{3}$ : A comparison of photoemission and Shubnikov-de Haas measurements. Phys. Rev. B 2010, 81, 205407. [CrossRef]

61. Berkowitz, J. Equilibrium Composition of Selenium Vapor; the Thermodynamics of the Vaporization of HgSe, CdSe, and SrSe. J. Chem. Phys. 1966, 45, 4289. [CrossRef]

62. Ginley, T.P.; Law, S. Growth of $\mathrm{Bi}_{2} \mathrm{Se}_{3}$ topological insulator films using a selenium cracker source. J. Vac. Sci. Technol. B Nanotechnol. Microelectron. Mater. Process. Meas. Phenom. 2016, 34, 02L105. [CrossRef]

63. Liu, X.; Smith, D.J.; Fan, J.; Zhang, Y.-H.; Cao, H.; Chen, Y.P.; Leiner, J.; Kirby, B.J.; Dobrowolska, M.; Furdyna, J.K. Structural properties of $\mathrm{Bi}_{2} \mathrm{Te}_{3}$ and $\mathrm{Bi}_{2} \mathrm{Se}_{3}$ topological insulators grown by molecular beam epitaxy on GaAs(001) substrates. Appl. Phys. Lett. 2011, 99, 171903. [CrossRef]

64. Liu, X.; Smith, D.J.; Cao, H.; Chen, Y.P.; Fan, J.; Zhang, Y.-H.; Pimpinella, R.E.; Dobrowolska, M.; Furdyna, J.K. Characterization of $\mathrm{Bi}_{2} \mathrm{Te}_{3}$ and $\mathrm{Bi}_{2} \mathrm{Se}_{3}$ topological insulators grown by MBE on (001) GaAs substrates. J. Vac. Sci. Technol. B 2012, 30, 02B103. [CrossRef]

65. Kim, N.; Lee, P.; Kim, Y.Y.; Kim, J.S.; Kim, Y.Y.; Noh, D.Y.; Yu, S.U.; Chung, J.; Kim, K.S. Persistent Topological Surface State at the Interface of $\mathrm{Bi}_{2} \mathrm{Se}_{3}$ Film Grown on Patterned Graphene. ACS Nano 2014, 8, 1154-1160. [CrossRef] [PubMed]

66. Song, C.-L.; Wang, Y.Y.-L.; Jiang, Y.-P.; Zhang, Y.; Chang, C.-Z.; Wang, L.; He, K.; Chen, X.; Jia, J.-F.; Wang, Y.Y.-L.; et al. Topological insulator $\mathrm{Bi}_{2} \mathrm{Se}_{3}$ thin films grown on double-layer graphene by molecular beam epitaxy. Appl. Phys. Lett. 2010, 97, 143118. [CrossRef]

67. Xie, M.-H.; Guo, X.; Xu, Z.-J.; Ho, W.-K. Molecular-beam epitaxy of topological insulator $\mathrm{Bi}_{2} \mathrm{Se}_{3}(111)$ and (221) thin films. Chin. Phys. B 2013, 22, 68101. [CrossRef]

68. Pashley, M.D.; Li, D. Control of the Fermi-level position on the GaAs(001) surface: Se passivation. J. Vac. Sci. Technol. A 1994, 12, 1848. [CrossRef]

69. Emziane, M.; Marsillac, S.; Bernède, J.C. Preparation of highly oriented $\alpha-\operatorname{In}_{2} \mathrm{Se}_{3}$ thin films by a simple technique. Mater. Chem. Phys. 2000, 62, 84-87. [CrossRef]

70. Jing, Y.; Huang, S.; Zhang, K.; Wu, J.; Guo, Y.; Peng, H.; Liu, Z.; Xu, H.Q. Weak antilocalization and electron-electron interaction in coupled multiple-channel transport in a $\mathrm{Bi}_{2} \mathrm{Se}_{3}$ thin film. Nanoscale 2016, 8 , 1879-1885. [CrossRef] [PubMed]

71. Wang, X.; He, X.; Guan, T.; Liao, J.; Lin, C.; Wu, K.; Li, Y.; Zeng, C. Transport properties of topological insulator $\mathrm{Bi}_{2} \mathrm{Se}_{3}$ thin films in tilted magnetic fields. Physica E 2012, 46, 236-240. [CrossRef]

72. Li, C.H.; van't Erve, O.M.J.; Robinson, J.T.; Liu, Y.; Li, L.; Jonker, B.T. Electrical detection of charge-current-induced spin polarization due to spin-momentum locking in $\mathrm{Bi}_{2} \mathrm{Se}_{3}$. Nat. Nanotechnol. 2014, 9, 218-224. [CrossRef] [PubMed]

73. Jerng, S.-K.; Joo, K.; Kim, Y.S.Y.; Yoon, S.-M.; Lee, J.H.; Kim, M.; Kim, J.S.; Yoon, E.; Chun, S.-H.; Kim, Y.S.Y. Ordered growth of topological insulator $\mathrm{Bi}_{2} \mathrm{Se}_{3}$ thin films on dielectric amorphous $\mathrm{SiO}_{2}$ by $\mathrm{MBE}$. Nanoscale 2013, 5, 10618. [CrossRef] [PubMed]

74. Liu, Y.H.; Chong, C.W.; Jheng, J.L.; Huang, S.Y.M.; Huang, J.C.A.; Li, Z.; Qiu, H.; Huang, S.Y.M.; Marchenkov, V.V. Gate-tunable coherent transport in Se-capped $\mathrm{Bi}_{2} \mathrm{Se}_{3}$ grown on amorphous $\mathrm{SiO}_{2} / \mathrm{Si}$. Appl. Phys. Lett. 2015, 107, 12106. [CrossRef]

75. Tabor, P.; Keenan, C.; Urazhdin, S.; Lederman, D.; Urazdhin, S.; Lederman, D. Molecular beam epitaxy and characterization of thin $\mathrm{Bi}_{2} \mathrm{Se}_{3}$ films on $\mathrm{Al}_{2} \mathrm{O}_{3}$ (110). Appl. Phys. Lett. 2011, 99, 13111. [CrossRef]

76. Glinka, Y.D.; Babakiray, S.; Lederman, D. Plasmon-enhanced electron-phonon coupling in Dirac surface states of the thin-film topological insulator $\mathrm{Bi}_{2} \mathrm{Se}_{3}$. J. Appl. Phys. 2015, 118, 135713. [CrossRef] 
77. He, L.; Xiu, F.; Yu, X.; Teague, M.; Jiang, W.; Fan, Y.; Kou, X.; Lang, M.; Wang, Y.; Huang, G.; et al. Surface-Dominated Conduction in a $6 \mathrm{~nm}$ thick $\mathrm{Bi}_{2} \mathrm{Se}_{3}$ Thin Film. Nano Lett. 2012, 12, 1486-1490. [CrossRef] [PubMed]

78. Park, B.C.; Kim, T.-H.; Sim, K.I.; Kang, B.; Kim, J.W.J.H.; Cho, B.; Jeong, K.-H.; Cho, M.-H.; Kim, J.W.J.H. Terahertz single conductance quantum and topological phase transitions in topological insulator $\mathrm{Bi}_{2} \mathrm{Se}_{3}$ ultrathin films. Nat. Commun. 2015, 6, 6552. [CrossRef] [PubMed]

79. Aabdin, Z.; Peranio, N.; Winkler, M.; Bessas, D.; König, J.; Hermann, R.P.; Böttner, H.; Eibl, O. Sb $2 \mathrm{Te}_{3}$ and $\mathrm{Bi}_{2} \mathrm{Te}_{3}$ Thin Films Grown by Room-Temperature MBE. J. Electron. Mater. 2012, 41, 1493-1497. [CrossRef]

80. Caha, O.; Dubroka, A.; Humlíček, J.; Holý, V.; Steiner, H.; Ul-Hassan, M.; Sánchez-Barriga, J.; Rader, O.; Stanislavchuk, T.N.; Sirenko, A.A.; et al. Growth, Structure, and Electronic Properties of Epitaxial Bismuth Telluride Topological Insulator Films on $\mathrm{BaF}_{2}(111)$ Substrates. Cryst. Growth Des. 2013, 13, 3365-3373. [CrossRef]

81. Fülöp, A.; Song, Y.; Charpentier, S.; Shi, P.; Ekström, M.; Galletti, L.; Arpaia, R.; Bauch, T.; Lombardi, F.; Wang, S. Phase transition of bismuth telluride thin films grown by MBE. Appl. Phys. Express 2014, 7, 45503. [CrossRef]

82. Kampmeier, J.; Weyrich, C.; Lanius, M.; Schall, M.; Neumann, E.; Mussler, G.; Schäpers, T.; Grützmacher, D. Selective area growth of $\mathrm{Bi}_{2} \mathrm{Te}_{3}$ and $\mathrm{Sb}_{2} \mathrm{Te}_{3}$ topological insulator thin films. J. Cryst. Growth 2016, 443, 38-42. [CrossRef]

83. Liu, H.W.; Yuan, H.T.; Fukui, N.; Zhang, L.; Jia, J.F.; Iwasa, Y.; Chen, M.W.; Hashizume, T.; Sakurai, T.; Xue, Q.K. Growth of Topological Insulator $\mathrm{Bi}_{2} \mathrm{Te}_{3}$ Ultrathin Films on $\mathrm{Si}(111)$ Investigated by Low-Energy Electron Microscopy. Cryst. Growth Des. 2010, 10, 4491-4493. [CrossRef]

84. Roy, A.; Guchhait, S.; Sonde, S.; Dey, R.; Pramanik, T.; Rai, A.; Movva, H.C.P.; Colombo, L.; Banerjee, S.K. Two-dimensional weak anti-localization in $\mathrm{Bi}_{2} \mathrm{Te}_{3}$ thin film grown on $\mathrm{Si}(111)-(7 \times 7)$ surface by molecular beam epitaxy. Appl. Phys. Lett. 2013, 102, 163118. [CrossRef]

85. Steiner, H.; Volobuev, V.; Caha, O.; Bauer, G.; Springholz, G.; Holý, V. Structure and composition of bismuth telluride topological insulators grown by molecular beam epitaxy. J. Appl. Crystallogr. 2014, 47, 1889-1900. [CrossRef]

86. Wang, K.L.; Liu, Y.; Wang, W.; Meyer, N.; Bao, L.H.; He, L.; Lang, M.R.; Chen, Z.G.; Che, X.Y.; Post, K.; et al. High-quality $\mathrm{Bi}_{2} \mathrm{Te}_{3}$ thin films grown on mica substrates for potential optoelectronic applications. Appl. Phys. Lett. 2013, 103, 31605. [CrossRef]

87. Yu, X.; He, L.; Lang, M.; Jiang, W.; Xiu, F.; Liao, Z.; Wang, Y.; Kou, X.; Zhang, P.; Tang, J.; et al. Separation of top and bottom surface conduction in $\mathrm{Bi}_{2} \mathrm{Te}_{3}$ thin films. Nanotechnology 2013, 24, 15705. [CrossRef] [PubMed]

88. Kim, Y.; DiVenere, A.; Wong, G.K.L.; Ketterson, J.B.; Cho, S.; Meyer, J.R. Structural and thermoelectric transport properties of $\mathrm{Sb}_{2} \mathrm{Te}_{3}$ thin films grown by molecular beam epitaxy. J. Appl. Phys. 2002, 91, 715-718. [CrossRef]

89. Zeng, Z.; Morgan, T.A.; Fan, D.; Li, C.; Hirono, Y.; Hu, X.; Zhao, Y.; Lee, J.S.; Wang, J.; Wang, Z.M.; et al. Molecular beam epitaxial growth of $\mathrm{Bi}_{2} \mathrm{Te}_{3}$ and $\mathrm{Sb}_{2} \mathrm{Te}_{3}$ topological insulators on GaAs (111) substrates: A potential route to fabricate topological insulator $p-n$ junction. AIP Adv. 2013, 3, 72112. [CrossRef]

90. Kong, D.; Dang, W.; Cha, J.J.; Li, H.; Meister, S.; Peng, H.; Liu, Z.; Cui, Y. Few-Layer Nanoplates of Bi ${ }_{2} \mathrm{Se}_{3}$ and $\mathrm{Bi}_{2} \mathrm{Te}_{3}$ with Highly Tunable Chemical Potential. Nano Lett. 2010, 10, 2245-2250. [CrossRef] [PubMed]

91. Steinberg, H.; Gardner, D.R.; Lee, Y.S.; Jarillo-Herrero, P. Surface State Transport and Ambipolar Electric Field Effect in $\mathrm{Bi}_{2} \mathrm{Se}_{3}$ Nanodevices. Nano Lett. 2010, 10, 5032-5036. [CrossRef] [PubMed]

92. Checkelsky, J.G.; Hor, Y.S.; Cava, R.J.; Ong, N.P. Bulk Band Gap and Surface State Conduction Observed in Voltage-Tuned Crystals of the Topological Insulator $\mathrm{Bi}_{2} \mathrm{Se}_{3}$. Phys. Rev. Lett. 2011, 106, 196801. [CrossRef] [PubMed]

93. Bansal, N.; Koirala, N.; Brahlek, M.; Han, M.-G.; Zhu, Y.; Cao, Y.; Waugh, J.; Dessau, D.S.; Oh, S. Robust topological surface states of $\mathrm{Bi}_{2} \mathrm{Se}_{3}$ thin films on amorphous $\mathrm{SiO}_{2} / \mathrm{Si}$ substrate and a large ambipolar gating effect. Appl. Phys. Lett. 2014, 104, 241606. [CrossRef]

94. Zhang, L.; Hammond, R.; Dolev, M.; Liu, M.; Palevski, A.; Kapitulnik, A. High quality ultrathin $\mathrm{Bi}_{2} \mathrm{Se}_{3}$ films on $\mathrm{CaF}_{2}$ and $\mathrm{CaF}_{2} / \mathrm{Si}$ by molecular beam epitaxy with a radio frequency cracker cell. Appl. Phys. Lett. 2012, 101, 153105. [CrossRef] 
95. Lee, J.J.; Schmitt, F.T.; Moore, R.G.; Vishik, I.M.; Ma, Y.; Shen, Z.X. Intrinsic ultrathin topological insulators grown via molecular beam epitaxy characterized by in-situ angle resolved photoemission spectroscopy. Appl. Phys. Lett. 2012, 101, 13118. [CrossRef]

96. Park, J.; Soh, Y.-A.; Aeppli, G.; Bland, S.R.; Zhu, X.-G.; Chen, X.; Xue, Q.-K.; Grey, F. Crystal structure and epitaxy of $\mathrm{Bi}_{2} \mathrm{Te}_{3}$ films grown on Si. Appl. Phys. Lett. 2012, 101, 221910. [CrossRef]

97. Chen, X.; Ma, X.-C.; He, K.; Jia, J.-F.; Xue, Q.-K. Molecular Beam Epitaxial Growth of Topological Insulators. Adv. Mater. 2011, 23, 1162-1165. [CrossRef] [PubMed]

98. Krumrain, J.; Mussler, G.; Borisova, S.; Stoica, T.; Plucinski, L.; Schneider, C.M.; Grützmacher, D. MBE growth optimization of topological insulator $\mathrm{Bi}_{2} \mathrm{Te}_{3}$ films. J. Cryst. Growth 2011, 324, 115-118. [CrossRef]

99. Li, Y.-Y.; Wang, G.; Zhu, X.-G.; Liu, M.-H.; Ye, C.; Chen, X.; Wang, Y.-Y.; He, K.; Wang, L.-L.; Ma, X.-C.; et al. Intrinsic topological insulator $\mathrm{Bi}_{2} \mathrm{Te}_{3}$ thin films on $\mathrm{Si}$ and their thickness limit. Adv. Mater. 2010, 22, 4002-4007. [CrossRef] [PubMed]

100. Liu, Y.; Bian, G.; Miller, T.; Bissen, M.; Chiang, T.-C. Topological limit of ultrathin quasi-free-standing $\mathrm{Bi}_{2} \mathrm{Te}_{3}$ films grown on Si(111). Phys. Rev. B 2012, 85, 195442. [CrossRef]

101. Liu, Y.; Wang, H.H.; Bian, G.; Zhang, Z.; Lee, S.S.; Fenter, P.A.; Tischler, J.Z.; Hong, H.; Chiang, T.C. Interfacial bonding and structure of $\mathrm{Bi}_{2} \mathrm{Te}_{3}$ topological insulator films on $\mathrm{Si}(111)$ determined by surface X-ray scattering. Phys. Rev. Lett. 2013, 110, 226103. [CrossRef] [PubMed]

102. Plucinski, L.; Mussler, G.; Krumrain, J.; Herdt, A.; Suga, S.; Grützmacher, D.; Schneider, C.M. Robust surface electronic properties of topological insulators: $\mathrm{Bi}_{2} \mathrm{Te}_{3}$ films grown by molecular beam epitaxy. Appl. Phys. Lett. 2011, 98, 222503. [CrossRef]

103. Harrison, S.E.; Li, S.; Huo, Y.; Zhou, B.; Chen, Y.L.; Harris, J.S. Two-step growth of high quality $\mathrm{Bi}_{2} \mathrm{Te}_{3}$ thin films on $\mathrm{Al}_{2} \mathrm{O}_{3}$ (0001) by molecular beam epitaxy. Appl. Phys. Lett. 2013, 102, 2011-2015. [CrossRef]

104. Ngabonziza, P.; Heimbuch, R.; de Jong, N.; Klaassen, R.A.; Stehno, M.P.; Snelder, M.; Solmaz, A.; Ramankutty, S.V.; Frantzeskakis, E.; van Heumen, E.; et al. In situ spectroscopy of intrinsic $\mathrm{Bi}_{2} \mathrm{Te}_{3}$ topological insulator thin films and impact of extrinsic defects. Phys. Rev. B 2015, 92, 35405. [CrossRef]

105. Xu, H.; Song, Y.; Gong, Q.; Pan, W.; Wu, X.; Wang, S. Raman spectroscopy of epitaxial topological insulator $\mathrm{Bi}_{2} \mathrm{Te}_{3}$ thin films on GaN substrates. Mod. Phys. Lett. B 2015, 29, 1550075. [CrossRef]

106. Collins-McIntyre, L.J.; Wang, W.; Zhou, B.; Speller, S.C.; Chen, Y.L.; Hesjedal, T. Growth of $\mathrm{Bi}_{2} \mathrm{Se}_{3}$ and $\mathrm{Bi}_{2} \mathrm{Te}_{3}$ on amorphous fused silica by MBE. Phys. Status Solidi B 2015, 252, 1334-1338. [CrossRef]

107. Rapacz, R.; Balin, K.; Wojtyniak, M.; Szade, J. Morphology and local conductance of single crystalline $\mathrm{Bi}_{2} \mathrm{Te}_{3}$ thin films on mica. Nanoscale 2015, 7, 16034-16038. [CrossRef] [PubMed]

108. Fornari, C.I.; Rappl, P.H.O.; Morelhão, S.L.; Abramof, E. Structural properties of $\mathrm{Bi}_{2} \mathrm{Te}_{3}$ topological insulator thin films grown by molecular beam epitaxy on (111) $\mathrm{BaF}_{2}$ substrates. J. Appl. Phys. 2016, 119, 165303. [CrossRef]

109. Wang, G.; Zhu, X.-G.; Sun, Y.-Y.; Li, Y.-Y.; Zhang, T.; Wen, J.; Chen, X.; He, K.; Wang, L.-L.; Ma, X.-C.; et al. Topological insulator thin films of $\mathrm{Bi}_{2} \mathrm{Te}_{3}$ with controlled electronic structure. Adv. Mater. 2011, 23, 2929-2932. [CrossRef] [PubMed]

110. Jiang, Y.; Sun, Y.Y.; Chen, M.; Wang, Y.; Li, Z.; Song, C.; He, K.; Wang, L.; Chen, X.; Xue, Q.-K.; et al. Fermi-Level Tuning of Epitaxial $\mathrm{Sb}_{2} \mathrm{Te}_{3}$ Thin Films on Graphene by Regulating Intrinsic Defects and Substrate Transfer Doping. Phys. Rev. Lett. 2012, 108, 66809. [CrossRef] [PubMed]

111. Chien, Y.-J.; Zhou, Z.; Uher, C. Growth and transport properties of $\mathrm{Sb}_{2-x} \mathrm{~V}_{x} \mathrm{Te}_{3}$ thin films on sapphire substrates. J. Cryst. Growth 2005, 283, 309-314. [CrossRef]

112. Taskin, A.A.; Sasaki, S.; Segawa, K.; Ando, Y. Manifestation of topological protection in transport properties of epitaxial $\mathrm{Bi}_{2} \mathrm{Se}_{3}$ thin films. Phys. Rev. Lett. 2012, 109, 066803. [CrossRef] [PubMed]

113. Bansal, N.; Kim, Y.S.; Brahlek, M.; Edrey, E.; Oh, S. Thickness-Independent Transport Channels in Topological Insulator $\mathrm{Bi}_{2} \mathrm{Se}_{3}$ Thin Films. Phys. Rev. Lett. 2012, 109, 116804. [CrossRef] [PubMed]

114. Xiong, J.; Luo, Y.; Khoo, Y.; Jia, S.; Cava, R.J.; Ong, N.P. High-field Shubnikov-de Haas oscillations in the topological insulator $\mathrm{Bi}_{2} \mathrm{Te}_{2}$ Se. Phys. Rev. B Condens. Matter Mater. Phys. 2012, 86, 045314. [CrossRef]

115. Brahlek, M.; Koirala, N.; Bansal, N.; Oh, S. Transport properties of topological insulators: Band bending, bulk metal-to-insulator transition, and weak anti-localization. Solid State Commun. 2015, 215, 54-62. [CrossRef]

116. Tung, Y.; Chiang, Y.F.; Chong, C.W.; Deng, Z.X.; Chen, Y.C.; Huang, J.C.A.; Cheng, C.-M.M.; Pi, T.-W.W.; Tsuei, K.-D.D.; Li, Z.; et al. Growth and characterization of molecular beam epitaxy-grown $\mathrm{Bi}_{2} \mathrm{Te}_{3-x} \mathrm{Se}_{x}$ topological insulator alloys. J. Appl. Phys. 2016, 119, 55303. [CrossRef] 
117. Ren, Z.; Taskin, A.A.; Sasaki, S.; Segawa, K.; Ando, Y. Large bulk resistivity and surface quantum oscillations in the topological insulator $\mathrm{Bi}_{2} \mathrm{Te}_{2}$ Se. Phys. Rev. B 2010, 82, 241306(R). [CrossRef]

118. Cha, J.J.; Kong, D.; Hong, S.-S.; Analytis, J.G.; Lai, K.; Cui, Y. Weak antilocalization in $\operatorname{Bi}_{2}(\operatorname{Se}(x) \operatorname{Te}(1-x))_{3}$ nanoribbons and nanoplates. Nano Lett. 2012, 12, 1107-1111. [CrossRef] [PubMed]

119. Zhang, J.; Chang, C.; Zhang, Z.; Wen, J.; Feng, X.; Li, K.; Liu, M.; He, K.; Wang, L.; Chen, X.; et al. Band structure engineering in $\left(\mathrm{Bi}_{1-x} \mathrm{Sb}_{x}\right)_{2} \mathrm{Te}_{3}$ ternary topological insulators. Nat. Commun. 2011, 2, 574. [CrossRef] [PubMed]

120. Kellner, J.; Eschbach, M.; Kampmeier, J.; Lanius, M.; Młyńczak, E.; Mussler, G.; Holländer, B.; Plucinski, L.; Liebmann, M.; Grützmacher, D.; et al. Tuning the Dirac point to the Fermi level in the ternary topological insulator $\left(\mathrm{Bi}_{1-x} \mathrm{Sb}_{x}\right)_{2} \mathrm{Te}_{3}$. Appl. Phys. Lett. 2015, 107, 251603. [CrossRef]

121. He, X.; Li, H.; Chen, L.; Wu, K. Substitution-induced spin-splitted surface states in topological insulator $\left(\mathrm{Bi}_{1-x} \mathrm{Sb}_{x}\right)_{2} \mathrm{Te}_{3}$. Sci. Rep. 2015, 5, 8830. [CrossRef] [PubMed]

122. Tang, J.; Chang, L.T.; Kou, X.; Murata, K.; Choi, E.S.; Lang, M.; Fan, Y.; Jiang, Y.; Montazeri, M.; Jiang, W.; et al. Electrical detection of spin-polarized surface states conduction in $\left(\mathrm{Bi}_{0.53} \mathrm{Sb}_{0.47}\right)_{2} \mathrm{Te}_{3}$ topological insulator. Nano Lett. 2014, 14, 5423-5429. [CrossRef] [PubMed]

123. Weyrich, C.; Drögeler, M.; Kampmeier, J.; Eschbach, M.; Mussler, G.; Merzenich, T.; Stoica, T.; Batov, I.E.; Schubert, J.; Plucinski, L.; et al. Growth, characterization, and transport properties of ternary $\left(\mathrm{Bi}_{1-x} \mathrm{Sb}_{x}\right)_{2} \mathrm{Te}_{3}$ topological insulator layers. J. Phys. Condens. Matter 2015, 28, 495501. [CrossRef] [PubMed]

124. Eschbach, M.; Młyńczak, E.; Kellner, J.; Kampmeier, J.; Lanius, M.; Neumann, E.; Weyrich, C.; Gehlmann, M.; Gospodarič, P.; Döring, S.; et al. Realization of a vertical topological $p-n$ junction in epitaxial $\mathrm{Sb}_{2} \mathrm{Te}_{3} / \mathrm{Bi}_{2} \mathrm{Te}_{3}$ heterostructures. Nat. Commun. 2015, 6, 8816. [CrossRef] [PubMed]

125. Lanius, M.; Kampmeier, J.; Weyrich, C.; Kölling, S.; Schall, M.; Schüffelgen, P.; Neumann, E.; Luysberg, M.; Mussler, G.; Koenraad, P.M.; et al. $p-n$ Junctions in Ultrathin Topological Insulator $\mathrm{Sb}_{2} \mathrm{Te}_{3} / \mathrm{Bi}_{2} \mathrm{Te}_{3}$ Heterostructures Grown by Molecular Beam Epitaxy. Cryst. Growth Des. 2016, 16, 2057-2061. [CrossRef]

126. Zhao, Y.; Liu, H.; Guo, X.; Jiang, Y.; Sun, Y.; Wang, H.; Wang, Y.; Li, H.-D.D.; Xie, M.-H.H.; Xie, X.-C.C.; et al. Crossover from 3D to 2D Quantum Transport in $\mathrm{Bi}_{2} \mathrm{Se}_{3} / \mathrm{In}_{2} \mathrm{Se}_{3}$ Superlattices. Nano Lett. 2014, 14, 5244-5249. [CrossRef] [PubMed]

127. Wang, Z.Y.; Guo, X.; Li, H.D.; Wong, T.L.; Wang, N.; Xie, M.H. Superlattices of $\mathrm{Bi}_{2} \mathrm{Se}_{3} / \mathrm{In}_{2} \mathrm{Se}_{3}$ : Growth characteristics and structural properties. Appl. Phys. Lett. 2011, 99, 023112. [CrossRef]

128. Brahlek, M.J.; Koirala, N.; Liu, J.; Yusufaly, T.I.; Salehi, M.; Han, M.G.; Zhu, Y.; Vanderbilt, D.; Oh, S. Tunable inverse topological heterostructure utilizing $\left(\mathrm{Bi}_{1-x} \mathrm{In}_{x}\right)_{2} \mathrm{Se}_{3}$ and multichannel weak-antilocalization effect. Phys. Rev. B 2016, 93, 125416. [CrossRef]

129. Li, H.D.; Wang, Z.Y.; Guo, X.; Wong, T.L.; Wang, N.; Xie, M.H. Growth of multilayers of $\mathrm{Bi}_{2} \mathrm{Se}_{3} / \mathrm{ZnSe}$ Heteroepitaxial interface formation and strain. Appl. Phys. Lett. 2011, 98, 043104. [CrossRef]

130. Chen, Z.; Garcia, T.A.; Hernandez-Mainet, L.C.; Zhao, L.; Deng, H.; Krusin-Elbaum, L.; Tamargo, M.C. Molecular beam epitaxial growth and characterization of $\mathrm{Bi}_{2} \mathrm{Se}_{3} / \mathrm{II}-\mathrm{VI}$ semiconductor heterostructures. Appl. Phys. Lett. 2014, 105, 242105. [CrossRef]

131. Luo, W.; Qi, X.L. Massive Dirac surface states in topological insulator/magnetic insulator heterostructures. Phys. Rev. B 2013, 87. [CrossRef]

132. Matetskiy, A.V.; Kibirev, I.A.; Hirahara, T.; Hasegawa, S.; Zotov, A.V.; Saranin, A.A. Direct observation of a gap opening in topological interface states of $\mathrm{MnSe} / \mathrm{Bi}_{2} \mathrm{Se}_{3}$ heterostructure. Appl. Phys. Lett. 2015, 107, 091604. [CrossRef]

133. Jiang, Z.; Chang, C.Z.; Tang, C.; Zheng, J.G.; Moodera, J.S.; Shi, J. Structural and proximity-induced ferromagnetic properties of topological insulator-magnetic insulator heterostructures. AIP Adv. 2016, 6, 055809. [CrossRef]

134. Chang, C.Z.; Tang, P.; Feng, X.; Li, K.; Ma, X.C.; Duan, W.; He, K.; Xue, Q.K. Band Engineering of Dirac Surface States in Topological-Insulator-Based van der Waals Heterostructures. Phys. Rev. Lett. 2015, 115, 136801. [CrossRef] [PubMed]

135. Kane, C.L.; Mele, E.J. Z $Z_{2}$ topological order and the quantum spin hall effect. Phys. Rev. Lett. 2005, 95, 146802. [CrossRef] [PubMed]

136. Chen, M.; Peng, J.P.; Zhang, H.M.; Wang, L.L.; He, K.; Ma, X.C.; Xue, Q.K. Molecular beam epitaxy of bilayer $\mathrm{Bi}(111)$ films on topological insulator $\mathrm{Bi}_{2} \mathrm{Te}_{3}$ : A scanning tunneling microscopy study. Appl. Phys. Lett. 2012, 101, 081603. [CrossRef] 
137. Wang, M.-X.; Li, P.; Xu, J.-P.; Liu, Z.-L.; Ge, J.-F.; Wang, G.-Y.; Yang, X.; Xu, Z.-A.; Ji, S.-H.; Gao, C.L.; et al. Interface structure of a topological insulator/superconductor heterostructure. New J. Phys. 2014, 16, 123043. [CrossRef]

138. Xu, S.-Y.; Alidoust, N.; Belopolski, I.; Richardella, A.; Liu, C.; Neupane, M.; Bian, G.; Huang, S.-H.; Sankar, R.; Fang, C.; et al. Momentum-space imaging of Cooper pairing in a half-Dirac-gas topological superconductor. Nat. Phys. 2014, 10, 943-950. [CrossRef]

139. Xu, J.P.; Liu, C.; Wang, M.X.; Ge, J.; Liu, Z.L.; Yang, X.; Chen, Y.; Liu, Y.; Xu, Z.A.; Gao, C.L.; et al. Artificial topological superconductor by the proximity effect. Phys. Rev. Lett. 2014, 112, 217001. [CrossRef]

140. Xu, J.P.; Wang, M.X.; Liu, Z.L.; Ge, J.F.; Yang, X.; Liu, C.; Xu, Z.A.; Guan, D.; Gao, C.L.; Qian, D.; et al. Experimental detection of a Majorana mode in the core of a magnetic vortex inside a topological insulator-superconductor $\mathrm{Bi}_{2} \mathrm{Te}_{3} / \mathrm{NbSe}_{2}$ heterostructure. Phys. Rev. Lett. 2015, 114, 017001. [CrossRef] [PubMed]

141. Xu, S.Y.; Liu, C.; Richardella, A.; Belopolski, I.; Alidoust, N.; Neupane, M.; Bian, G.; Samarth, N.; Hasan, M.Z. Fermi-level electronic structure of a topological-insulator/cuprate-superconductor based heterostructure in the superconducting proximity effect regime. Phys. Rev. B 2014, 90, 085128. [CrossRef]

142. Yilmaz, T.; Pletikosic, I.; Weber, A.P.; Sadowski, J.T.; Gu, G.D.; Caruso, A.N.; Sinkovic, B.; Valla, T. Absence of a proximity effect for a thin-films of a $\mathrm{Bi}_{2} \mathrm{Se}_{3}$ topological insulator grown on top of a $\mathrm{Bi}_{2} \mathrm{Sr}_{2} \mathrm{CaCu}_{2} \mathrm{O}_{8+\delta}$ cuprate superconductor. Phys. Rev. Lett. 2014, 113, 067003. [CrossRef] [PubMed]

(C) 2016 by the authors; licensee MDPI, Basel, Switzerland. This article is an open access article distributed under the terms and conditions of the Creative Commons Attribution (CC-BY) license (http:/ / creativecommons.org/licenses/by/4.0/). 